\title{
Patterns of Bubble Bursting and Weak Explosive Activity in an Active Lava Lake-Halema'uma'u, Killauea, 2015
}

Chapter $\mathrm{E}$ of

The 2008-2018 Summit Lava Lake at Kỉlauea Volcano, Hawai'i

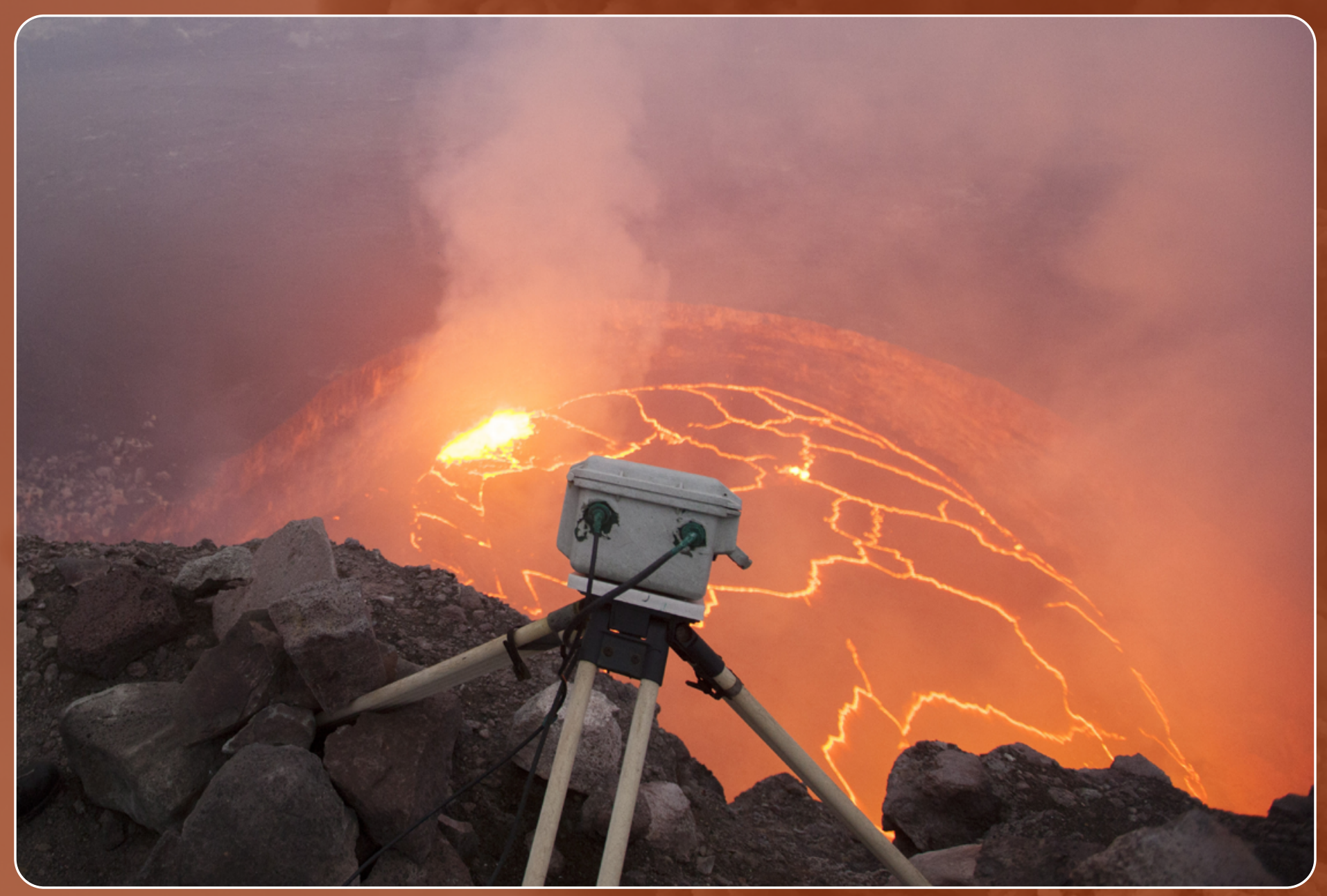

Professional Paper 1867 
Cover. View of the telemetered webcam (HMcam) monitoring the lava lake in the Overlook crater. Photograph by Hawaiian Volcano Observatory volunteer David Dow on October 23, 2012. 


\section{Patterns of Bubble Bursting and Weak Explosive Activity in an Active Lava Lake-Halema'uma'u, Kïlauea, 2015}

By Bianca G. Mintz, Bruce F. Houghton, Edward W. Llewellin, Tim R. Orr, Jacopo Taddeucci, Rebecca J. Carey, Ulrich Kueppers, Damien Gaudin, Matthew R. Patrick, Michael Burton, Piergiorgio Scarlato, and Alessandro La Spina

Chapter E of

The 2008-2018 Summit Lava Lake at Kīlauea Volcano, Hawai'i

Edited by Matthew Patrick, Tim Orr, Don Swanson, and Bruce Houghton

Professional Paper 1867

U.S. Department of the Interior

U.S. Geological Survey 


\section{U.S. Geological Survey, Reston, Virginia: 2021}

For more information on the USGS-the Federal source for science about the Earth, its natural and living resources, natural hazards, and the environment-visit https://www.usgs.gov or call 1-888-ASK-USGS (1-888-275-8747).

For an overview of USGS information products, including maps, imagery, and publications, visit https://store.usgs.gov.

Any use of trade, firm, or product names is for descriptive purposes only and does not imply endorsement by the U.S. Government.

Although this information product, for the most part, is in the public domain, it also may contain copyrighted materials as noted in the text. Permission to reproduce copyrighted items must be secured from the copyright owner.

Suggested citation:

Mintz, B.G., Houghton, B.F., Llewellin, E.W., Orr, T.R., Taddeucci, J., Carey, R.J., Kueppers, U., Gaudin, D., Patrick, M.R., Burton, M., Scarlato, P., and La Spina, A., 2021, Patterns of bubble bursting and weak explosive activity in an active lava lake-Halema'uma'u, Kïlauea, 2015, chap. E of Patrick, M., Orr, T., Swanson, D., and Houghton, B., eds., The 2008-2018 summit lava lake at Kīlauea Volcano, Hawaiii: U.S. Geological Survey Professional Paper 1867, 16 p., https://doi.org/10.3133/pp1867E.

ISSN 1044-9612 (print)

ISSN 2330-7102 (online) 


\section{Acknowledgments}

We thank numerous colleagues at the Hawaiian Volcano Observatory, University of Hawaili, and Instituto Nazionale di Geofisica e Vulcanologia for their contributions to the larger Stromboli-Kilauea project, especially Daniele Andronico, Wendy Cockshell, Elisabetta Del Bello, Sebastien Biass, Marie Edmonds, Samantha Isgett, Sebastian Mueller, Carolyn Parcheta, Tullio Ricci, Don Swanson, Caroline Tisdale, and Brett Walker. The authors would like to acknowledge grants from the National Science Foundation (EAR-0409303, 0810332, 1145159, 1427357, and 1829188) and the American Recovery and Reinvestment Act of 2009 (113153 via the Hawaiian Volcano Observatory), that funded this research. We are grateful to the Hawai'i Volcanoes National Park for access to Halema'uma'u Crater. We highly appreciate insightful reviews by Greg Waite and Einat Lev.

\section{Contents}

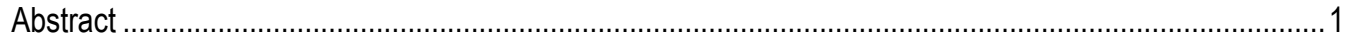

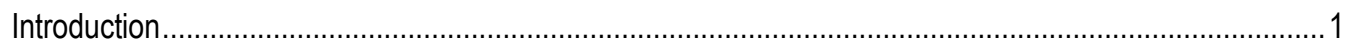

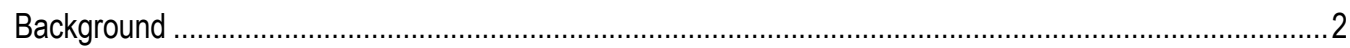

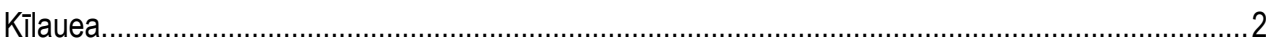



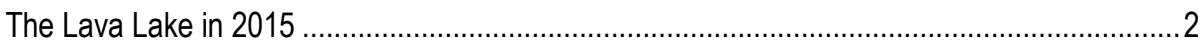

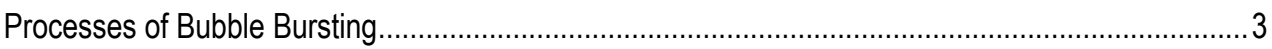

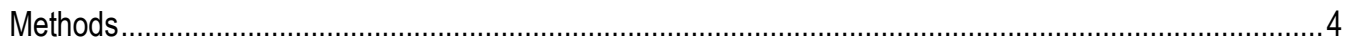

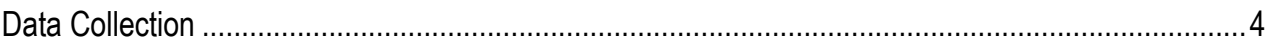

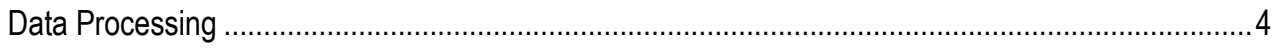

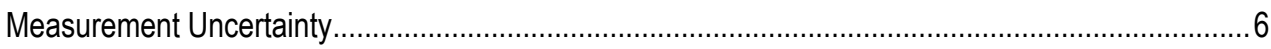

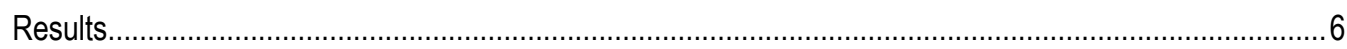

Temporal and Spatial Distribution of Activity over a 24-Hour Window ........................................... 6

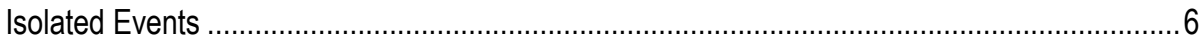

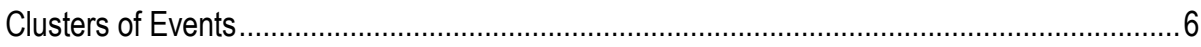

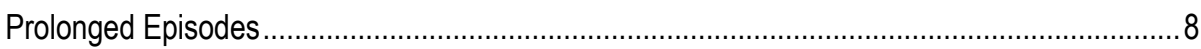

Overall Patterns of Eruptive Behavior at the Lava Lake in April ........................................... 8

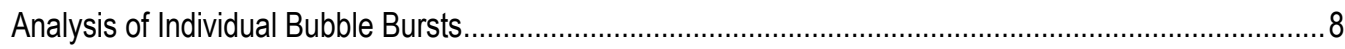

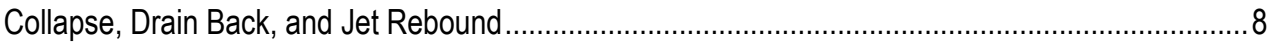

Relation to the 24-Hour Patterns of Lava Lake Behavior ........................................................... 10

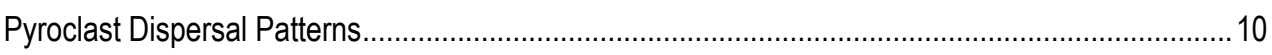

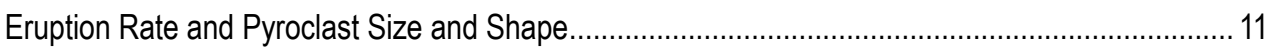

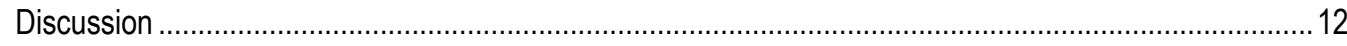

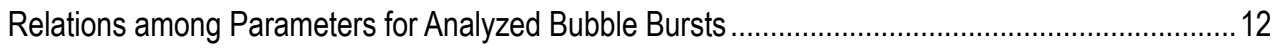

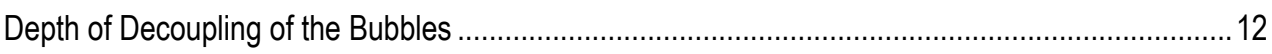

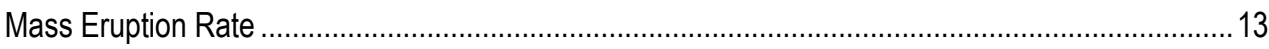

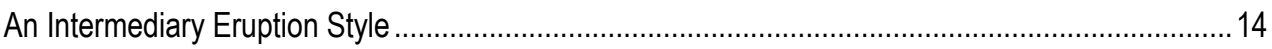



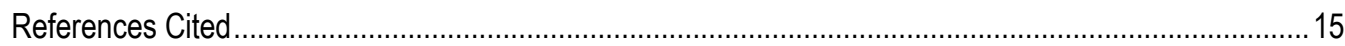




\section{Figures}

1. Map showing the locations of Kīlauea Caldera, Halema'uma'u Crater, and Overlook crater and photograph of the lava lake within Overlook crater....

2. Schematic diagrams and images of observed bubble burst sequence .................................... 3

3. Map showing camera locations along the Halema'uma'u Crater rim.......................................5

4. Frames from the near-infrared Hawaiian Volcano Observatory webcam ...................................6

5. Plots of bubble burst event frequency and bubble rise velocity ............................................ 9

6. Plot of cumulative mass percent versus grain size for bubble bursting events at Halema'uma'u........ 11

7. Plots of bubble bursting parameters ........................................................................... 13

8. Plot of duration and mass of basaltic activity at select volcanoes ........................................... 14

\section{Tables}

1. Videos and bubble bursting events 9

2. Physical parameters of the bubble bursting events ............................................................. 9

3. Best-fit parameters and associated uncertainties for fits of equation 1 to bubble burst event data ..... 10 


\section{Conversion Factors}

International System of Units to U.S. customary units

\begin{tabular}{|c|c|c|}
\hline Multiply & By & To obtain \\
\hline \multicolumn{3}{|c|}{ Length } \\
\hline centimeter $(\mathrm{cm})$ & 0.3937 & inch (in.) \\
\hline meter $(\mathrm{m})$ & 3.281 & foot $(\mathrm{ft})$ \\
\hline kilometer (km) & 0.6214 & mile (mi) \\
\hline meter $(\mathrm{m})$ & 1.094 & yard (yd) \\
\hline \multicolumn{3}{|c|}{ Area } \\
\hline square meter $\left(\mathrm{m}^{2}\right)$ & 10.76 & square foot $\left(\mathrm{ft}^{2}\right)$ \\
\hline square meter $\left(\mathrm{m}^{2}\right)$ & 0.0002471 & acre \\
\hline \multicolumn{3}{|c|}{ Volume } \\
\hline cubic kilometer $\left(\mathrm{km}^{3}\right)$ & 0.2399 & cubic mile $\left(\mathrm{mi}^{3}\right)$ \\
\hline \multicolumn{3}{|c|}{ Flow rate } \\
\hline meter per second $(\mathrm{m} / \mathrm{s})$ & 3.281 & foot per second (ft/s) \\
\hline \multicolumn{3}{|c|}{ Mass } \\
\hline kilogram (kg) & 2.205 & pound avoirdupois (lb) \\
\hline \multicolumn{3}{|c|}{ Density } \\
\hline kilogram per cubic meter $\left(\mathrm{kg} / \mathrm{m}^{3}\right)$ & 0.06242 & pound per cubic foot $\left(\mathrm{lb} / \mathrm{ft}^{3}\right)$ \\
\hline gram per cubic centimeter $\left(\mathrm{g} / \mathrm{cm}^{3}\right)$ & 62.4220 & pound per cubic foot $\left(\mathrm{lb} / \mathrm{ft}^{3}\right)$ \\
\hline
\end{tabular}

Temperature in degrees Celsius $\left({ }^{\circ} \mathrm{C}\right)$ may be converted to degrees Fahrenheit $\left({ }^{\circ} \mathrm{F}\right)$ as follows:

$$
{ }^{\circ} \mathrm{F}=\left(1.8 \times{ }^{\circ} \mathrm{C}\right)+32 \text {. }
$$

\section{Abbreviations}

$\begin{array}{ll}\text { GPS } & \text { Global Positioning System } \\ \text { HST } & \text { Hawaii Standard Tlme } \\ \text { HVO } & \text { Hawaiian Volcano Observatory } \\ \mathrm{IR} & \text { infrared } \\ \mathrm{kg} & \text { kilogram } \\ \mathrm{kg} / \mathrm{m}^{3} & \text { kilogram per cubic meter } \\ \mathrm{kg} / \mathrm{s} & \text { kilogram per second } \\ \mathrm{m} & \text { meter } \\ \mathrm{m}^{2} & \text { square meter } \\ \mathrm{m} / \mathrm{s} & \text { meter per second } \\ \mathrm{s} & \text { second }\end{array}$





\title{
Patterns of Bubble Bursting and Weak Explosive Activity in an Active Lava Lake-Halema'uma'u, Kïlauea, 2015
}

\author{
By Bianca G. Mintz, ${ }^{1}$ Bruce F. Houghton, ${ }^{1}$ Edward W. Llewellin, ${ }^{2}$ Tim R. Orr, ${ }^{3}$ Jacopo Taddeucci, ${ }^{4}$ Rebecca J. Carey, ${ }^{5}$ Ulrich \\ Kueppers, ${ }^{6}$ Damien Gaudin, ${ }^{6}$ Matthew R. Patrick, ${ }^{3}$ Michael Burton, ${ }^{7}$ Piergiorgio Scarlato, ${ }^{4}$ and Alessandro La Spina ${ }^{4}$
}

\section{Abstract}

The rise of the Halema' uma' $u$ lava lake in 2013-2018 to depths commonly 40 meters or less below the rim of the vent was an excellent opportunity to study outgassing and the link to associated eruptive activity. We use videography to investigate the rise and bursting of bubbles through the free surface of the lake in 2015. We focus on low-energy explosive activity (spattering) in which the ascent and bursting of meter-sized, mechanically decoupled bubbles trigger the ejection of fluidal bombs to tens of meters above the free surface. A decay in initial pyroclast velocity with time follows the same functional form as that observed for ejecta at Stromboli (Italy), suggesting a similar bubble-burst mechanism. We also find that the upward velocity of the bubble crust as it bursts is around 2.5 times higher than the velocity of the bubble as it rises through the lake surface, indicating that the bubbles are over-pressurized. Prior to bursting, bubbles emerge at velocities of 4 to 14 meters per second, suggesting rise from depths of at least tens of meters but unaffected by the deeper circulation of the lava lake.

We identify three styles of bubble bursting: (1) isolated, widely spaced, single bursts, (2) recurring clusters of discrete bubbles, and (3) prolonged episodes of overlapping bubble bursts along elongate narrow sources typically parallel to the margins of the lava lake. We call these styles of bursting isolated events, clusters, and prolonged episodes, respectively. The frequency of bubble bursting and the mass fluxes of gas and pyroclasts increase from styles 1 to 3 . The intensity (mass eruption rate) for single bubble bursts ranges from 280 to 3,500 kilograms per second. The total erupted mass of pyroclasts for a single burst is $<4,000$ kilograms $(\mathrm{kg})$ and for a single well-constrained prolonged episode is about $10^{7} \mathrm{~kg}$. These numbers place the observed spattering at the lowest end of basaltic explosivity in terms of erupted mass (that is, magnitude). Most ejecta fell back into the crater; only strands of Pele's hair rose to heights where they could be advected downwind from the vent.

\footnotetext{
${ }^{1}$ University of Hawai' $i$ at Honolulu, U.S.A.

${ }^{2}$ Durham University, United Kingdom.

${ }^{3}$ U.S. Geological Survey, U.S.A.

${ }^{4}$ Istituto Nazionale di Geofisica e Vulcanologia, Italy.

${ }^{5}$ University of Tasmania, Australia.

${ }^{6}$ Ludwig-Maximilians-Universität München, Germany.

${ }^{7}$ University of Manchester, United Kingdom.
}

Collectively, the explosive activity accompanying the three styles of bubble bursting spans from impulsive, transient eruptive behaviors to sustained discharge; this shift represents progressively higher frequency and intensity of bubble bursting.

\section{Introduction}

Strombolian and Hawaiian eruption styles differ principally in terms of eruptive duration (Houghton and others, 2016; Taddeucci and others, 2015). Normal explosions at Stromboli volcano are 1 to 3 orders of magnitude shorter in duration than Hawaiian episodes (most typically tens of seconds versus hours). We have identified and quantified patterns of bubble-bursting activity at Halema' uma' $u$ that are intermediate in duration and so bridge the gap between canonical Strombolian and Hawaiian eruption styles (Houghton and others, 2016). This style of activity has not previously been described in detail and has not been named beyond use of informal terms such as "spattering."

These classical weak explosive eruption styles were first defined based on purely qualitative observations (for example, Mercalli, 1881; Macdonald, 1972) at their type locations at Kīlauea and Mauna Loa, in Hawai 'i, and at Stromboli, in Italy. Later, Walker (1973) established a quantitative classification scheme for explosive eruptions based on tephra dispersal area and degree of fragmentation. Within that scheme, Strombolian explosions and Hawaiian fountains are considered the two end members of the spectrum of weakly explosive mafic eruptions. Strombolian explosions are characteristic of several volcanoes, including Stromboli (Italy), Etna (Italy), Erebus (Antarctica), and Yasur (Vanuatu) (Houghton and others, 2016). Hawaiian fountaining is common during eruptions at Mauna Loa and Kỉlauea volcanoes in Hawai' $i$, as well as at Etna, and Piton de la Fournaise in La Reunion (France) (Houghton and others, 2016).

Strombolian eruptions are transient, discrete explosions that are typically seconds in duration, which result from the release of gas from bursting pressurized bubbles. Hawaiian fountains can rise to above 500 meters $(\mathrm{m})$ and are prolonged but commonly episodic, with alternating periods of activity and repose of variable duration, typically from hours to days (Taddeucci and others, 2015). Pyroclasts from Strombolian and Hawaiian eruptions are similar in size and dispersal, reaching as much as a meter in diameter. Strombolian ejection velocities typically range from 
50 to 100 meters per second $(\mathrm{m} / \mathrm{s})$, though velocities of as much as $400 \mathrm{~m} / \mathrm{s}$ have been documented (Taddeucci and others, 2015). There are no accurate measurements of exit velocities for high fountains at Kîlauea but values as high as $258 \mathrm{~m} / \mathrm{s}$ have been estimated at Etna (Bonaccorso and Calvari, 2013). Lava lakes are commonly characterized by widely spaced Strombolian explosions of varying intensity, although Villarrica volcano (Chile) shows a range of discrete to sustained bubble-bursting activity similar to Halema'uma'u (Palma and others, 2008).

\section{Background}

\section{Kīlauea}

Kîlauea is an active shield volcano (Poland and others, 2014) and contains a summit caldera within which the Halema'uma' $u$ Crater is situated. Killauea is one of the most active volcanoes in the world, having repaved 90 percent of its surface with new lava in the last 1,000 years (Holcomb, 1987). The East Rift Zone of the volcano erupted almost continuously in a single eruptive sequence between 1983 and May 2018. This paper focuses on a concurrent eruption in Halema'uma'u Crater from March 19, 2008, until May 2018.

\section{8-2018 Summit Eruption}

The eruption began at 02:58 Hawaii Standard Time (HST) on March 19, 2008, with a small explosion, following months of increased summit seismic tremor and gas emissions. The explosion left a new 35-m-wide crater (Overlook crater) (Houghton and others, 2011; Patrick and others, 2013) near the base of the Halema'uma'u Crater wall (fig. 1A, B). Lava was first observed in July 2008 and was measured at a depth of about $200 \mathrm{~m}$ below the rim in 2009 (Patrick and others, 2013). During the early years of lava lake activity, when the surface of the lava lake was relatively deep within the crater, short-lived explosive activity (Houghton and others, 2013) was commonly triggered by rock fall events (Orr and others, 2013) into the lake.

By the end of 2013, wall collapses had widened the new crater to $215 \mathrm{~m}$ (northwest-southeast) by $160 \mathrm{~m}$ (northeastsouthwest). The lava lake was approximately the same diameter as the crater and mostly remained between 30 and $60 \mathrm{~m}$ below overflow (Patrick and others, 2013). The lava lake overflowed briefly onto the Halema'uma'u Crater floor in April 2015 and October 2016 (Patrick and others, 2021). The crater continued to widen; in October 2016 it had dimensions of $\sim 255 \mathrm{~m}$ by $\sim 195 \mathrm{~m}$. The higher lake levels from 2013 allowed for detailed observation and quantification of outgassing and weak explosive activity at the lava lake. The summit eruption ended when the lava lake withdrew during May 2018 and major subsidence followed, engulfing the Halema'uma' $u$ and Overlook craters (Neal and others, 2019).

\section{The Lava Lake in 2015}

The Halema'uma' $u$ lava lake underwent a variety of dynamic behaviors. The surface of the lava lake was covered in dark crustal plates tens of meters wide and centimeters thick (Patrick and others, 2018). The plates met along sutures where passive outgassing occurred (Patrick and others, 2018). The lava lake surface maintained a general flow direction (based on plate motion) from north to south, as upwelling generally occurred along the north margin of the lake and downwelling along the south margin (Patrick and others, 2018), particularly at the southeast margin of the lake, informally referred to as the "southeast sink." The plates

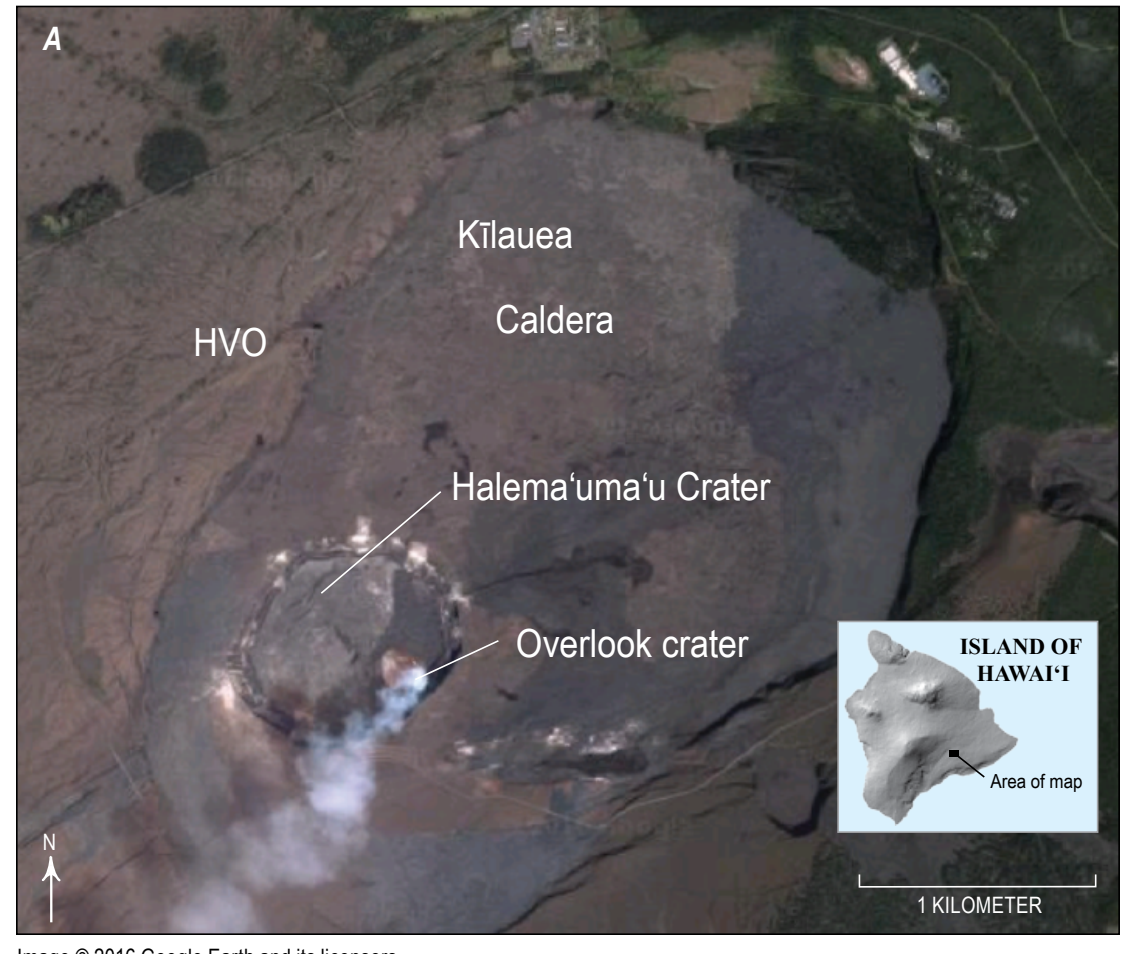

Image @ 2016 Google Earth and its licensors

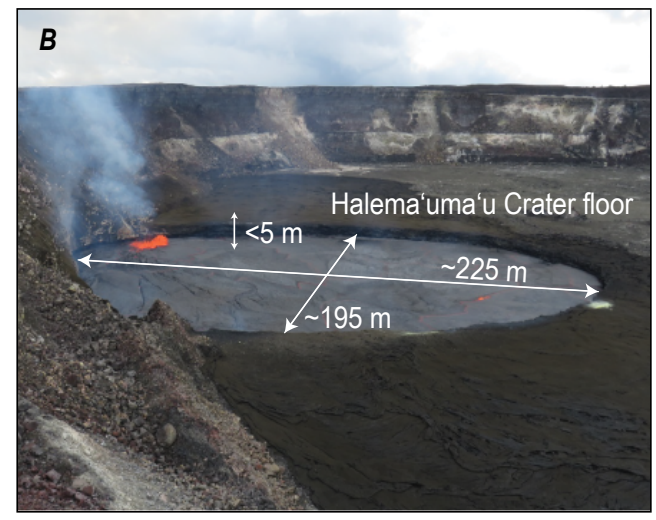

Figure 1. A, Image showing the locations of Kilauea Caldera, Halema'uma'u Crater, and Overlook crater. $B$, U.S. Geological Survey photograph of the lava lake within Overlook crater taken on September 10, 2016. Note the outgassing activity along the south margin of the lava lake. Distances are in meters (m). HVO, Hawaiian Volcano Observatory. 
were transported by convective motion within the underlying lake, but partial and complete reversals of plate motion were not uncommon (Patrick and others, 2018).

Outgassing occurred in a range of forms including:

1. Near-continuous passive outgassing (through the sutures between plates).

2. Frequent rise of decimeter-sized, isolated bubbles to reach the free surface. These bubbles either were advected beneath the crust toward the plate margins or burst through the lake surface; this could be observed most clearly at night as small, short-lived, incandescent holes that "speckle" the crustal plates.

3. Bursting of meter-sized bubbles through the viscoelastic crust. These larger bubbles rose more rapidly and ejected fluid bombs on bursting.

Passive outgassing (1) accounted for about one-third of measured sulfur dioxide $\left(\mathrm{SO}_{2}\right)$ emissions from the lava lake and the more vigorous forms of outgassing accounting for the remaining twothirds of $\mathrm{SO}_{2}$ emissions (Patrick and others, 2016). We focus here on the behavior of the meter-sized, mechanically decoupled gas bubbles as they rose through, and interacted with, the free surface of the lava lake.

\section{Processes of Bubble Bursting}

Since the 1950s, chemical and nuclear engineers have studied the bursting of bubbles, usually at an air-water interface (for example, Kientzler and others, 1954; Mason, 1954). Georgescu and others (2001) define three stages in bubble bursting

1. The approaching stage, defined by the arrival of the bubble at the free surface simultaneously with deformation of the liquid free surface. Before bursting occurs, the bubble oscillates vertically with a very small amplitude.

2. The thinning stage, which starts with drainage of the liquid film cap that reduces the film thickness down to a certain critical value and finishes with film disintegration and ejection of film droplets.

3. The break-up stage, which includes the bubble cavity collapse process that creates a rebounding unstable liquid jet, which splits up into several jet drops.

Deike and others (2018) summarize the linked processes as (A) "... a bubble reaches the free surface," (B) "the thin liquid film separating the bubble from the atmosphere drains," and (C) "disintegrates producing film drops." This process "leaves an unstable opened cavity," which (D) "collapses and throws jet drops mainly vertically above the surface, through the formation and eventually the break-up of a rising jet."

We see stages 1 through 3 and A through D very clearly in the Halema'uma'u bubble bursts despite obvious 3-4 orders-of-magnitude contrasts in bubble size and in viscosity. We refer to the fundamental unit of a single bubble bursting through the free surface at Halema' uma' $u$ as a bubblebursting event (event for short). An event consists of (1) an initial doming up of the free surface (fig. 2E), (2) appearance of the upper part of the bubble, stretching and thinning the crust above it (fig. $2 F$ ), (3) tearing and (or) fragmenting of the crust and outgassing, generating a cavity and ejected pyroclasts derived from the fragmenting crust (fig. $2 G$ ), and (4) collapse of the cavity, drainage of melt, and, in many cases, formation of a rebounding bubble jet (fig. $2 H$ ), which generally does not fragment.
A

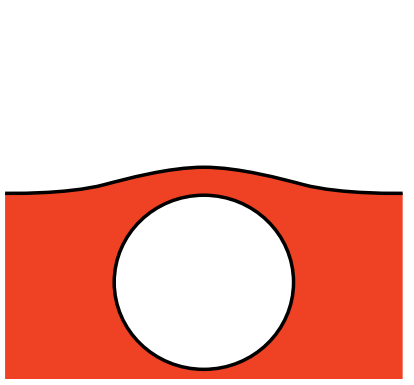

E
B



$\boldsymbol{F}$

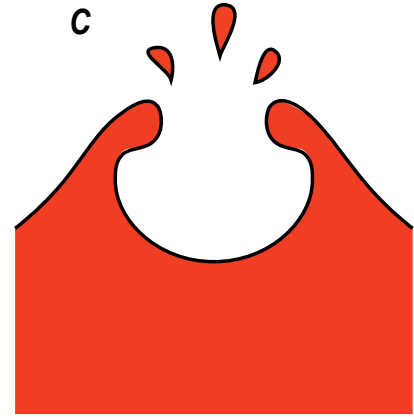

G
D

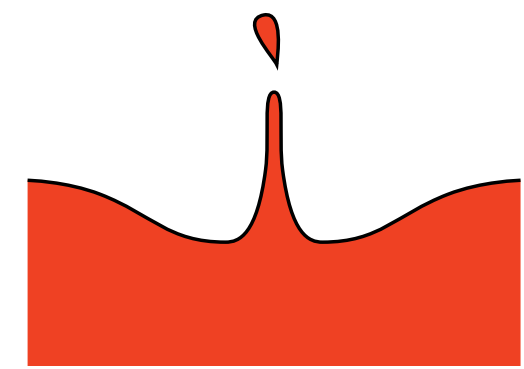

H

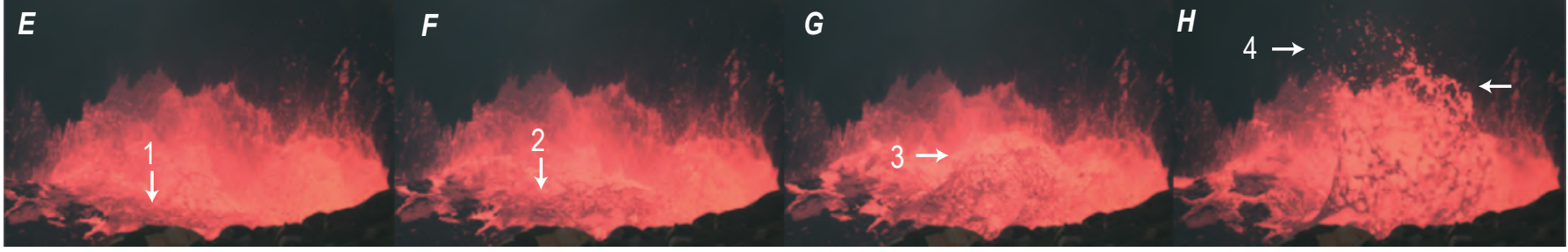

Figure 2. Schematic and observed bubble burst sequence, with time progressing from left to right. $A$, Bubble approaches the free surface, causing it to dome upward. B, Liquid film drains and thins. C, Liquid film disintegrates and retracts, ejecting droplets. D, Cavity collapses and forms a sub-vertical rebounding bubble jet that may break into further droplets. Drafted after images by Deike and others (2018). Still frames from a high-speed video of a bubble-burst event at Halema'uma'u on December 2015 show the same sequence. E, Initial doming at time (t) of 0 seconds (s). $F$, Pre-burst at $t=0.116 \mathrm{~s}$. G, Bubble burst at $\mathrm{t}=0.202 \mathrm{~s}$. $H$, Rebounding bubble jet at $\mathrm{t}=1.040 \mathrm{~s}$. Brighter tones represent hotter surfaces. Field of view is 4.6 meters wide in all images. Arrows indicate the location of discrete bursting bubbles, which are numbered in order of appearance. 
Patterns of Bubble Bursting and Weak Explosive Activity in an Active Lava Lake—Halema'uma'u, Kilauea, 2015

\section{Methods}

\section{Data Collection}

Our observations occurred in April and December 2015. Besides visual observation, the rise and bursting of metersized bubbles were captured via high-speed videos, filmed with a Phantom M120 camera. During field deployments, the camera was set up at various locations along the rim of Halema' uma'u Crater (fig. 3). The camera location in each case was recorded with a Global Positioning System (GPS) unit, accurate to within $10 \mathrm{~m}$, and a laser range finder was used to measure the distance and azimuth to the free surface of the lava lake. The videos were recorded at 200 and 500 frames per second and 1,920 $\times 1,200$-pixel resolution. A total of 22 videos were recorded between April 24 and 25, 2015, and 39 videos between December 7 and 8 . For the April deployment, this corresponds to a field of view of about $70 \times 45 \mathrm{~m}$; videos acquired in December have a field of view of about $20 \times 12 \mathrm{~m}$.

All the high-speed videos focused on bubble bursts and associated spattering activity at the lake margin. The highspeed videos from April 24 were centered on the north part of the lava lake. The high-speed videos filmed during the December 8 deployment captured activity in the southeast sink. Low-resolution versions of the four videos (videos I-IV) are available at https://doi.org/10.3133/pp1867E.

A webcam operating in a near-infrared (IR) "night" mode (StarDot NetCam SC webcam; station HMcam) was maintained on the southeast rim of Halema'uma' $u$ as part of the Hawaiian Volcano Observatory's (HVO) general monitoring program until 2018 (fig. 3). The camera has a field of view that includes most of the lava lake. A small fraction of the south part of the lava lake, including the southeast sink, is blocked from the webcam's view by the wall of Halema'uma'u Crater. We manually analyzed webcam images from a 24-hour-long period from 22:55 HST on April 23, 2015, to 22:55 HST on April 24, 2015, in order to put the activity captured in the high-speed videos into the context of a 24-hour time frame. At that time, the camera was collecting images at 1 frame per second with 1,296 $\times 960$-pixel resolution. A low-resolution video (Video_24hr_HMcam) created from the images is available at https://doi.org/10.3133/pp1867E.

We also used images spanning the 24-hour period of December 10, 2015, collected by a thermal-IR camera (Mikron M7500L webcam; station HTcam) that is part of HVO's monitoring program. The December 10 images have a native resolution of $320 \times 240$ pixels and were archived at 1 frame per minute. The IR camera was positioned on the rim of Halema'uma' $u$ Crater about $60 \mathrm{~m}$ southwest of the webcam (fig. 3). This manual analysis was performed to add context for the December high-speed videos, similar to that added to the April videos by the webcam images. A low-resolution video (Video_24hr_HTcam) created from the images is available at https://doi.org/10.3133/pp1867E.

\section{Data Processing}

Individual high-speed video frames were extracted using the Phantom Camera Control application and loaded into the ImageJ open source image processing program (Abramoff and others, 2004) for analyses. The arrival of a bubble at the free surface is first identified by a doming of the surface, which may be incandescent, or capped by a crust. The duration of an event was measured as the time from the onset of doming (when the free surface first visibly started to rise owing to the arrival of decoupled gas bubbles) to when the free surface first began to collapse back down, just after the bubble burst. Dimensions of the doming surface above the bubble were measured in ImageJ until just prior to bursting. We measured the diameter of the domed surface parallel to the free surface (where the doming lava surface meets the free surface). The maximum height is measured at the center of the doming surface in the plane perpendicular to the axis of the camera's line of sight. The cross-sectional area of the doming surface (used to approximate the cross-sectional area of the bubble) is calculated using the area formula for an ellipse: $(\pi \times$ (major semi-axis) $\times($ minor semi-axis)). The major semi-axis is taken as half the diameter of the domed surface and the minor semi-axis as half its height. Most, if not all, of the bubble is encased within the doming surface at bursting, based on the video footage.

We measured bubble rise velocities, initial velocities of pyroclasts, and velocity of the rebound jet related to drainage of adjacent melt into the resulting void using MTrackJ, a plug-in for ImageJ that allows manual tracking of features and calculates velocity from the spatial difference between equivalent points in successive images and the elapsed time. Bubble rise velocities, inferred from the rate at which the free surface ascends upward (regardless of whether the surface is capped by a crust or not), are measured from when deformation of the upward-doming surface is first visible at the free surface. The bubble rise velocity is taken as the first velocity recorded when the lava surface first begins to dome. The bubble bursting velocity is defined as the velocity of the surface when the bubble bursts. The pyroclast initial velocity was calculated only for sharply defined pyroclasts, and is the velocity measured at the point of detachment from the crust; this was only a subset of all clasts visible in any image.

Imagery was analyzed to determine geometric information about the observed pyroclasts, and to calculate mass eruption rate. For each event, three to four images were selected at 0.1 second intervals, when large numbers of pyroclasts were visible. Most of the pyroclasts visible in each image were manually colored in black, whereas the rest of the image was converted to white, using Adobe Photoshop. The binary image was then loaded into ImageJ. We calculated the following shape factors for each pyroclast: area, perimeter, major and minor axes, and equivalent circular diameter (that is, the diameter of a circle with the same cross-sectional area as the pyroclast, calculated as $\sqrt{2 \times \text { Area } \div \pi}$ ). Because the images are in two dimensions, pyroclast volumes were approximated by multiplying the 




Base image $\odot 2016$ Google Earth and its licensors

Figure 3. Map showing camera locations along the Halema'uma'u Crater rim. The red circle shows the position of the high-speed Phantom M120 camera deployed on April 24, 2015, and the red line shows the horizontal distance between the camera and the activity. The same camera was also deployed on December 8, 2015, as indicated by the green circle, with the horizontal distance between the camera and the activity indicated by the green line. The long-term positions of Hawaiian Volcano Observatory's StarDot NetCam SC webcam (HMcam) and Mikron M7500L webcam (HTcam) are indicated by the blue and yellow dots, respectively. The approximate field of view for each webcam is outlined with solid lines; the dashed lines simply show the distance between the camera and the approximate field of view.

measured cross-sectional area first by the minor axis, then by the major axis, and taking the mean volume; the uncertainty is taken as the difference between the mean and maximum or minimum values.

The total mass of pyroclasts, or the erupted mass, was calculated from the video frame that showed the greatest number of pyroclasts (the peak frame). Pyroclast volumes were converted to mass using the measured density of juvenile clasts ejected during infrequent larger explosions triggered by collapse of the walls of the crater. An average mass eruption rate was calculated for each event by dividing mass of pyroclasts in the peak frame by the elapsed time between the onset of bubble bursting and the peak frame. This assumes no clasts had been lost from the jet and that no additional pyroclasts were ejected by that time, which is consistent with the video evidence. 


\section{Measurement Uncertainty}

The dominant uncertainties in our measurements are because of the limits on temporal and spatial resolution of the videos. The high-speed videos collected in April 2015 (capturing events A-E, described in the Results section below) were filmed at 200 frames per second so the minimum uncertainty on the timing of observations is $\pm 1 / 200$ seconds. The position of features within the videos can be estimated to within 10 pixels, which gives an uncertainty on distance and position measurements of $\pm 0.38 \mathrm{~m}$. For the high-speed videos collected in December 2015 (capturing events $\mathrm{F}$ and $\mathrm{G}$ ), the equivalent uncertainties are 1/500 seconds and $0.1 \mathrm{~m}$. The time uncertainty on the near-IR and on the thermal-IR cameras is \pm 1 second, but imagery from these cameras was not used for quantitative determination of position or distance. Uncertainty on velocities derived from the Phantom imagery allows for propagation of fractional uncertainties on time interval and distance travelled between start and end frames in MTrackJ. Uncertainty on bubble area is derived from the uncertainties for the measurements of absolute distance. All measured velocities are two-dimensional projections on the plane perpendicular to the camera line of sight, and thus represent lower bounds of the real, three-dimensional velocity fields.

\section{Results}

Based on our observations, we identified three patterns or styles of bubble bursting defined by the temporal and spatial distribution of events: isolated events, short-lived clusters of events, and prolonged episodes. The presentation of the results reflects this primary categorization.

Some events were widely separated in time and space; we call these isolated events. Isolated events threw fluidal bombs to heights of meters to a few tens of meters above the collapsing bubble. The bursts typically lasted for a few tenths of a second to seconds, with relatively long repose intervals of seconds to minutes.

Events could also be variably grouped in time and space; we identified two patterns: clusters and prolonged episodes. Clusters were repeated bubble bursts grouped around a narrow, commonly point, source and were closely spaced in time. They also projected bombs meters to a few tens of meters into the air. Episodes (or prolonged episodes) were protracted groupings of numerous bubble bursts that were tightly linked in space and time. They contained the most intense events, producing repeated, and commonly overlapping ejection of jets of pyroclasts to meters to tens of meters in height. Prolonged episodes tended to extend along arcs parallel to the lake margin but have been observed in the interior of the lava lake, and commonly migrated with the prevailing lava lake circulation. They commonly persisted for tens of minutes to hours. Video observations, combined with geophysical (seismic and infrasound) measurements (Patrick and others, 2016), indicated that the lava lake as a whole shifted between periods of spattering behaviors as we describe here and weakly spattering regimes, where large bubble bursts are absent. Pyroclasts ejected from the lava lake mostly fell back into the lake.

\section{Temporal and Spatial Distribution of Activity over a 24-Hour Window}

\section{Isolated Events}

All isolated events were measured on webcam images during a 24-hour period from 22:55 HST on April 23 through 22:55 HST on April 24, 2015, totaling 1,760 events. The median duration of these events was 5.0 seconds (fig. $4 A$ ). The longest event lasted for about 20 seconds, though it is possible that all events with durations longer than 15 seconds were closely spaced clusters of bubble bursts (that is, clusters of events). The shortest event that could be detected is observed in only a single frame and so must have a duration of $<2$ seconds.

Isolated events occurred throughout the 24-hour period, and commonly recurred at single locations (fig. $4 B$ ). The longest amount of time without any isolated events lasted for about 25 seconds, and only happened when other forms of activity (clusters of events and prolonged episodes) were occurring elsewhere. Isolated events occurred throughout the lava lake (fig. $4 A, B$ ), but most commonly in the north part where upwelling occurs.

\section{Clusters of Events}

A total of 161 clusters were recorded during April 23-24, 2015 , using both temporal and spatial information. The weakest clusters of events generally contained 2 to 6 individual events. Clusters of events of greater intensity, and generally longer durations, were composed of more frequent events, making it harder to accurately distinguish and quantify individual events, because of the video's slow frame rate. The motion of the clusters was not coupled with that of the crustal plates; no clusters of events travelled across the lava lake or moved away from their point source. The median duration of clusters of events (fig. 4C) was 35.6 seconds, ranging between 1 second and 567 seconds (9.45 minutes). Clusters of events occurred throughout the lava

Figure 4. Frames from the near-infrared Hawaiian Volcano Observatory webcam (HMcam). Points are overlain to show where on the lava lake's surface the activity occurred during the 24-hour study period from April 23 to April 24. Points in the upper four panels are color coded to show: durations of isolated events $(A)$; frequencies of isolated events at each location $(B)$; durations of clusters of events $(C)$; and frequencies of clusters of events at each location $(D)$. Warm colors indicate longer durations and greater frequencies than cool colors, respectively. Note that the colors in each image represent different numerical values. Images in the lower three panels depict the sources and paths for the 21 prolonged episodes (numbered in order of occurrence) within the 24 hours from April 23 to April 24: prolonged episodes 1 to $6(E)$; prolonged episodes 7 to 13 ( $F$ ); and prolonged episodes 14 to 21 (G). Episode 5 initially formed separately but then combined with episode 2 . Episodes 18 and 21 durations are calculated up to when they left the field of view. Likely they did not last much longer, having disappeared close to the southeast sink. 


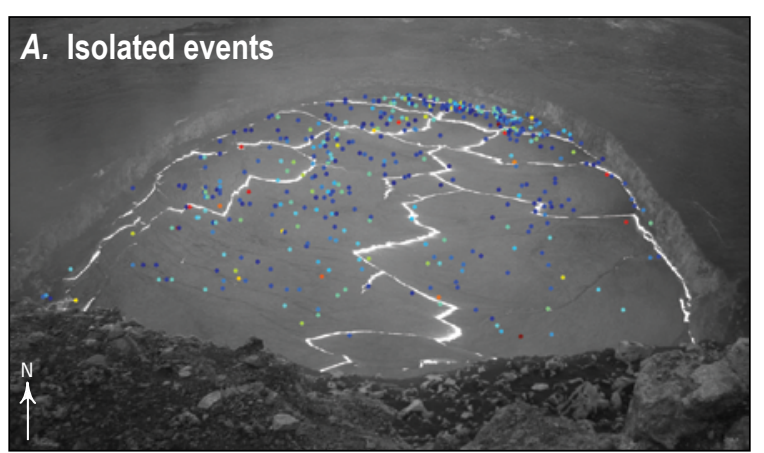

EXPLANATION

Duration, in seconds


EXPLANATION

Duration, in seconds

$\begin{array}{lllll}500 & 400 & 300 & 200 & 100\end{array}$
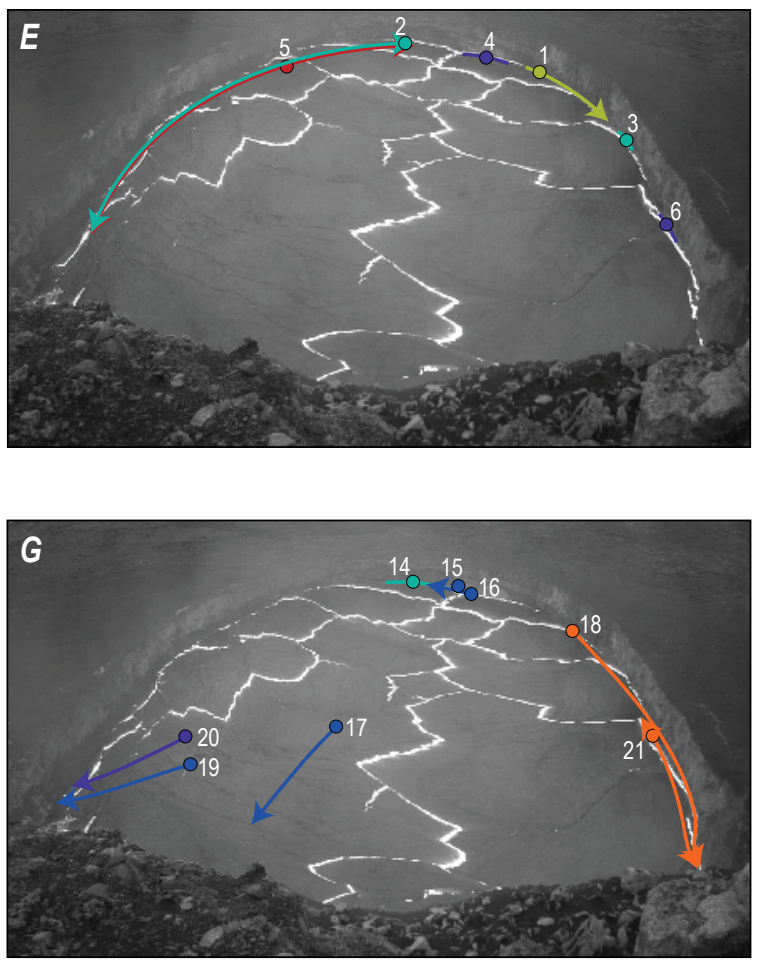

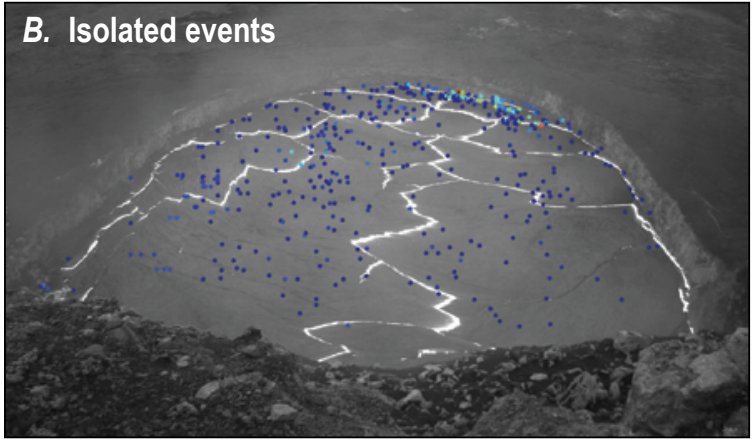

EXPLANATION

Frequency, per hour
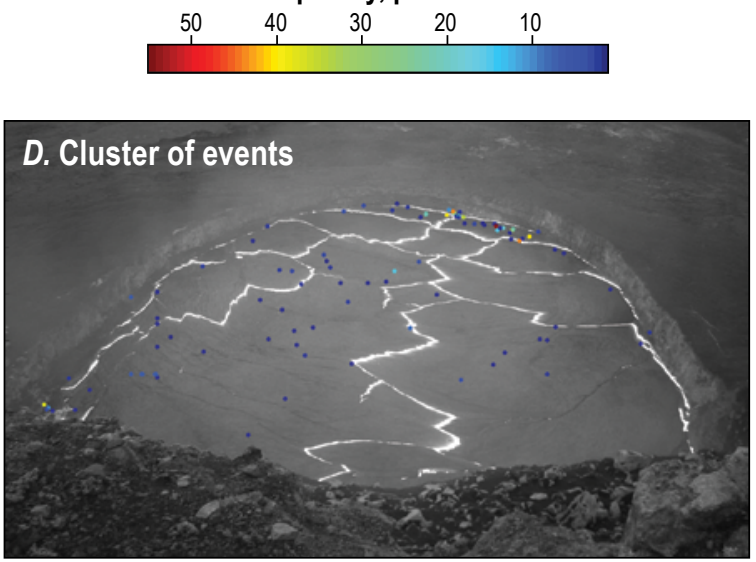

EXPLANATION

Frequency, per hour
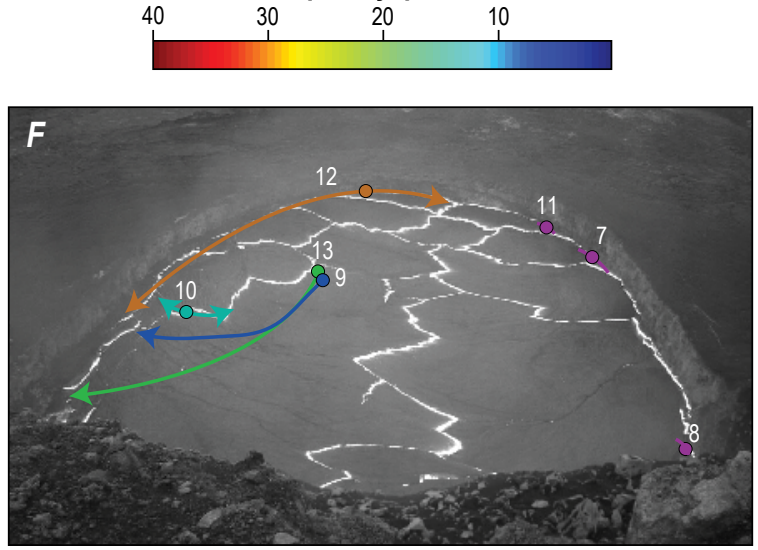

EXPLANATION

Episode

Duration

$\longleftarrow$ Travel path-Direction and

(or) expansion $\quad 1$ to $<5$ minutes

$<1$ minute

○ Origin
5 to $<10$ minutes

10 to $<30$ minutes

30 minutes to $<1$ hour

1 to $<2$ hours

2 to $<3$ hours

3 to $<4$ hours

4 hours or more 
lake, but favored the lake margins (fig. $4 C, D$ ). Clusters were most commonly observed in the west half of the lava lake, especially far south along the west margin.

\section{Prolonged Episodes}

Twenty-one prolonged episodes were recorded within the 24-hour period of April 23 to 24, 2015 (fig. 4E-G). The median duration of episodes was about 6.8 minutes. The prolonged episode with the longest duration lasted for about 5.1 hours. The prolonged episode with the shortest duration lasted for 23 seconds. Despite its short duration, the 23-second episode is still considered a prolonged episode based on its spatial characteristics and intensity. Typically, the events composing prolonged episodes were markedly stronger in intensity and greater in number than the events that compose clusters.

Isolated events and clusters were too short lived to be constrained accurately by the thermal camera (operating at 1 frame per minute) on December 10, 2015, but thermal images showed very similar durations for prolonged episodes. A total of 29 episodes was observed during the 24 hours of December 10. The mean duration was about 42 minutes, the maximum was 5.3 hours, and the minimum approximately 1 minute (limited by the frame rate).

Prolonged episodes that travelled commonly followed similar paths, moving with the general convective flow direction of the lake surface. However, a few episodes travelled both against and with the lake's general flow direction. Sources for most episodes formed along the lake margin; some then travelled along the lake margin, whereas other sources remained stationary. Sources that formed away from the lake margin did not travel directly toward the southeast sink, but rather were drawn toward the nearest lake margin while moving generally southward. Sources for prolonged episodes also changed in length throughout their lifespans.

\section{Overall Patterns of Eruptive Behavior at the Lava Lake in April}

The frequency of isolated events (number of events per hour) increased through the 24 hours on April 23-24, 2015 (fig. 5A). Frequency increased drastically between hours 6 and 7 ; after hour 7, the average frequency of isolated events was almost an order of magnitude higher than before hour 6 . In general, duration also increased through the 24 -hour period. The longest isolated events, with durations of 10 seconds or greater, steadily increased in frequency over the course of the 24 hours. However, isolated events lasting less than 10 seconds were the most common.

The frequency of clusters and prolonged episodes was variable over the 24 hours, and no systematic behavior was evident (fig. 5B). There does not appear to be any correlation among the frequencies of isolated events, clusters, and prolonged episodes.

In summary, at the start of the April 23-24, 2015, analysis period, the frequency of all types of activity at the lava lake was relatively low. The frequency in isolated events increased around hour 6. Clusters of events saw the greatest frequency in hour 12. No additional prolonged episodes formed after hour 16.

\section{Analysis of Individual Bubble Bursts}

We analyzed in detail seven events (A to $G$ ) from four highspeed videos (I to IV). Videos I and II, which were recorded on April 24, 2015, focus on regions in the north part of the lava lake; both videos lasted for 18.26 seconds. Video I includes a single isolated event (event A). Video II records part of a prolonged episode, from which we selected four events to investigate in greater detail (events B, C, D, and E). Videos III and IV were recorded on December 8,2015 , and captured isolated events occurring in the southeast sink (events F and G, respectively). Details of the videos are summarized in table 1, and data derived from the videos are presented in table 2.

Inspection of the data for all seven bubble burst events shows no apparent trend in bubble rise velocity with time for any of the events (fig. 5C). Consequently, the bubble rise velocity associated with each event is taken as the mean of the velocity data for that bubble, and the standard deviation of the data is taken as the uncertainty on that value. By contrast, there is a consistent inverse trend in pyroclast initial velocities with time after burst onset for all events. The trend in pyroclast initial velocities is reminiscent of that observed by Taddeucci and others (2012) for pyroclasts ejected by explosion pulses in Strombolian activity (for example, their fig. 3). They analysed the decay profile using an equation developed by AlatorreIbargüengoitia and others (2010) for pyroclasts ejected in shocktube experiments:

$$
v=\frac{v_{0}}{1+\frac{v_{0}}{h} t}
$$

where $v$ is the initial velocity of a pyroclast ejected at time $t$ after the onset of bursting, $v_{0}$ is the theoretical initial velocity of a pyroclast ejected at $t=0$, and $h$ is a length parameter, which Taddeucci and others (2012) identify as the height of the bubble at the point of burst.

We fit equation 1 to each bubble burst event dataset in turn, using a non-linear least-squares approach as outlined by Kemmer and Keller (2010). This allows us to determine best-fit values for $v_{0}$ and $h$, and 95-percent confidence intervals on the parameter values, which we adopt as uncertainties. Table 3 gives the best fit values and uncertainties for each event; $h$ values have a range of 2-6 m, except for event E, which was insufficiently constrained to allow meaningful 95-percent confidence intervals to be determined.

\section{Collapse, Drain Back, and Jet Rebound}

We also characterized two other phenomena - drain back and jet rebound. Drain back is the flow or drainage of magma back into the collapsing cavity that forms after a bubble bursts through the free surface (fig. 2C). Upon bursting, the melt surrounding 

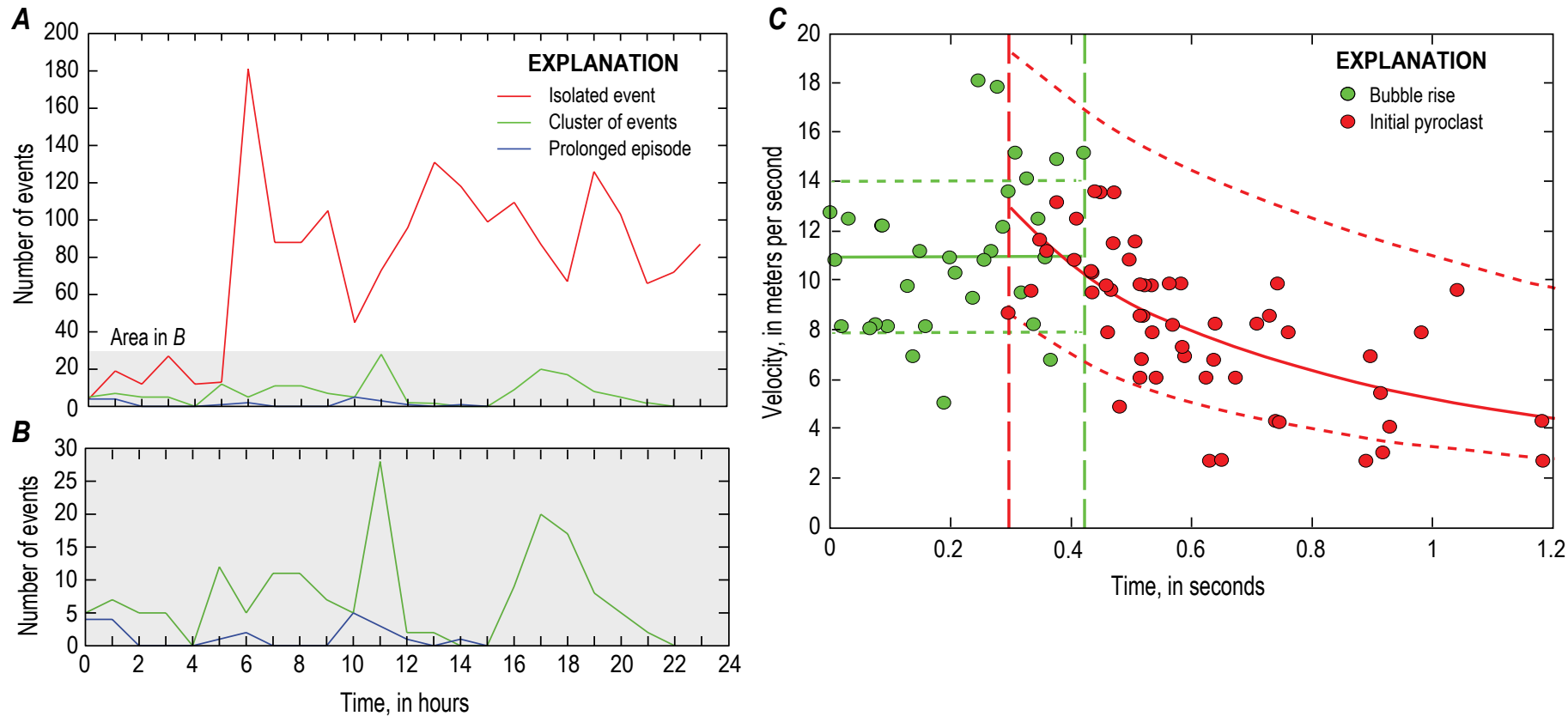

Figure 5. A, Plot of frequency of isolated events, clusters of events, and prolonged episodes versus time for the 24-hour analysis from April 23 to April 24. $B$, Zoomed-in view of lower part of plot $A$ showing the frequency of clusters of events and prolonged episodes versus time. $C$, Bubble rise velocity (green) and initial pyroclast velocity (red) over time for event $F$. Solid green line shows mean of rise velocity, dashed green lines show \pm 1 standard deviation. Solid red line shows best fit of equation 1 to initial pyroclast velocity data, dotted red lines show 95-percent confidence interval. Green and red long-dashed lines show end of bubble rise and onset of pyroclast formation, respectively.

Table 1. Videos and bubble bursting events.

[Times are in Hawaii Standard Time (HST)]

\begin{tabular}{clclll}
\hline Video & Date and time of filming & $\begin{array}{c}\text { Video duration, } \\
\text { in seconds }\end{array}$ & Event & Event type & Event location \\
\hline I & April 24, 2015, at 08:47 & 18.26 & A & Isolated event & North part \\
II & April 24, 2015, at 09:22 & 18.26 & B, C, D, and E & $\begin{array}{c}\text { Events during one prolonged } \\
\text { episode }\end{array}$ & $\begin{array}{c}\text { Started in the north part then } \\
\text { migrated to the west }\end{array}$ \\
& & & & Isolated event & Southeast sink \\
III & December 8, 2015, at 13:16 & 7.30 & $\mathrm{~F}$ & Isolated event & Southeast sink \\
IV & December 8, 2015, at 14:28 & 7.30 & $\mathrm{G}$ & & \\
\hline
\end{tabular}

Table 2. Physical parameters of the bubble bursting events.

[m, meter; m/s, meter per second; $\mathrm{m}^{2}$, square meter; kg, kilogram; kg/s, kilogram per second]

\begin{tabular}{|c|c|c|c|c|c|c|c|}
\hline Parameter & Event A & Event B & Event C & Event D & Event E & Event $\mathrm{F}$ & Event G \\
\hline Mean bubble rise velocity $(\mathrm{m} / \mathrm{s})$ & $3.7 \pm 1.6$ & $10.0 \pm 4.0$ & $9.4 \pm 6.7$ & $6.1 \pm 2.0$ & $10.9 \pm 3.1^{\mathrm{a}}$ & $10.9 \pm 3.1$ & $14.3 \pm 7.3$ \\
\hline Bubble bursting velocity $(\mathrm{m} / \mathrm{s})$ & $6.1 \pm 1.0$ & $16.2 \pm 2.6$ & $20.3^{b}$ & $9.8 \pm 0.9$ & $14.3 \pm 3.1^{\mathrm{a}}$ & $18.1 \pm 0.3$ & $36.2 \pm 0.5$ \\
\hline Bubble height (m) & $2.1 \pm 0.38$ & $1.2 \pm 0.38$ & $1.6 \pm 0.38$ & $1.9 \pm 0.38$ & $5.2 \pm 0.38^{\mathrm{a}}$ & $4.1 \pm 0.10$ & $3.4 \pm 0.10$ \\
\hline Bubble area $\left(\mathrm{m}^{2}\right)$ & $5.6 \pm 1.2$ & $2.6 \pm 0.9$ & $4.1 \pm 1.1$ & $4.3 \pm 1.0$ & $12.5 \pm 1.2^{\mathrm{a}}$ & $15.8 \pm 0.5$ & $15.8 \pm 0.5$ \\
\hline $\begin{array}{l}\text { Median pyroclast equivalent circular diameter } \\
\quad \text { (range) }(\mathrm{m})\end{array}$ & $\begin{array}{l}0.28(0.20- \\
1.76)\end{array}$ & $\begin{array}{l}0.30(0.08- \\
1.98)\end{array}$ & $\begin{array}{l}0.32(0.14 \\
1.16)\end{array}$ & $\begin{array}{l}0.40(0.12- \\
2.10)\end{array}$ & $\begin{array}{l}0.64(0.26- \\
2.90)\end{array}$ & $\begin{array}{l}0.12(0.04- \\
3.46)\end{array}$ & $\begin{array}{l}0.10(0.02- \\
\quad 3.28)\end{array}$ \\
\hline Total erupted mass to peak $(\mathrm{kg})$ & 202 & 343 & 192 & 1,187 & 1,039 & 3,680 & 3,845 \\
\hline Time to peak (s) & 0.67 & 0.975 & 0.69 & 1.05 & 0.45 & 1.044 & 1.132 \\
\hline Average mass eruption rate $(\mathrm{kg} / \mathrm{s})$ & 301 & 352 & 278 & 1,130 & 2,309 & 3,525 & 3,397 \\
\hline
\end{tabular}

${ }^{a}$ Values represent the northwest half of event E.

bUncertainty on bubble bursting velocity could not be estimated for event $\mathrm{C}$.

${ }^{\mathrm{C}}$ Rebound was not observed for event $\mathrm{G}$. 
Table 3. Best-fit parameters and associated uncertainties for fits of equation 1 to bubble burst event data.

[m, meter; $\mathrm{m} / \mathrm{s}$, meter per second; \%, percent; -, not determined]

\begin{tabular}{ccccc}
\hline $\begin{array}{c}\text { Burst } \\
\text { event }\end{array}$ & $\begin{array}{c}\text { Maximum initial velocity, } v_{0} \\
(\mathbf{m} / \mathbf{s})\end{array}$ & $\begin{array}{c}95 \% \text { confidence interval on } v_{0} \\
(\mathbf{m} / \mathbf{s})\end{array}$ & $\begin{array}{c}\text { Bubble height parameter, } h \\
(\mathbf{m})\end{array}$ & $\begin{array}{c}95 \% \text { confidence interval on } h \\
(\mathbf{m})\end{array}$ \\
\hline A & 11.1 & $7.7-15.2$ & 2.4 & $1.6-4.9$ \\
B & 12.0 & $9.0-15.3$ & 2.4 & $1.9-3.5$ \\
C & 14.2 & $10.3-18.6$ & 1.9 & $1.5-3.0$ \\
D & 24.2 & $16.7-32.6$ & 4.6 & $3.5-7.5$ \\
E & 8.1 & - & 9.0 & - \\
F & 13.0 & $8.7-19.3$ & 6.1 & $3.6-17.6$ \\
G & 18.3 & $14.4-21.9$ & 4.1 & $3.0-6.7$ \\
\hline
\end{tabular}

the cavity is no longer supported by the gas pressure within the bubble; hence, the bubble cavity collapses and melt flows into the newly created void. This occurs with every event, regardless of whether that event is isolated or part of a cluster or prolonged episode. As the cavity is collapsing, some of the melt may be projected vertically (Orr and others, 2014), which we refer to as a rebounding bubble jet (fig. $2 D$ ). This projected melt rises as an independent jet, but generally does not fragment and instead simply descends after reaching a peak height. No pyroclasts were associated with the jet rebounds from any of the events described here. Rebound velocities ( 4 to $7 \mathrm{~m} / \mathrm{s}$ ) and heights $(1.8$ to $4.2 \mathrm{~m}$ ) are given in table 2 .

\section{Relation to the 24-Hour Patterns of Lava Lake Behavior}

Event A was one of the 1,760 isolated events to occur within a 24-hour window at the lava lake on April 23-24. This event occurred in the upwelling region near the north edge of the lava lake, close to the crater wall, where many similar events took place. At 08:47 HST the high-speed camera captured the event; 0.2 seconds later, the crust (having been disturbed by the event) began to reform and at least four relatively small isolated events, all ejecting pyroclasts, occurred along the edges of the original area of activity. These events were possibly enabled by the bursting of event $\mathrm{A}$, which left a depressurized, or more porous area in the lava lake for small bubbles to rise and burst through. Event A lasted for 2.45 seconds.

Events B, C, D, and E were part of a prolonged episode (episode 12 in fig. $4 F$ ) that lasted for 2.29 hours. Episode 12 was slightly longer than the 24-hour average of 1.74 hours for prolonged episodes but still within one standard deviation. The episode (recorded in video II) began at 09:01:18 HST and was originally focused on a single point source along the north lake margin. By about 24 seconds after onset, the spattering had elongated parallel to the margin and increased in height. The spattering continued to expand and split into two separate spattering sources at 09:04:52 HST. One source moved east (along the lake margin) toward the center of the upwelling area of the lava lake and then died, whereas the other migrated along the margin of the lava lake with the prevailing flow direction toward the west and south, continuing to grow and increase in vigor. The four discrete bubble bursting events quantified below occurred during this part of the episode, when the source was $23 \mathrm{~m}$ long. At 10:19:33 HST, the source again split into two, but recombined at 10:26:11 HST. Afterward, the source continued to migrate along the west lake margin toward the south but died at about 11:18:47 HST (after 34 seconds of waning) without reaching the southeast sink. The frame rate on HVO's 24-hour webcam was too low to determine how many events made up the episode. The high-speed camera recorded 28 events during the 18.26 seconds the camera was filming. Assuming the rate at which events occur is consistent over the duration of a prolonged episode's life, more than 12,000 events may have made up the episode during the 2.29 hours that it lasted. Note that the many events that make up a prolonged episode overlap with each other in space and time.

Video III was recorded at 13:16 HST on December 8 for 7.30 seconds. The video captured event $\mathrm{F}$, which occurred in the center of the southeast sink. In addition to event $F$, there were four other notable observed events, two of which occurred on the west side of the southeast sink and were partly obscured by the overhang. A third occurred on the east edge of the sink. The fourth occurred in the center of the sink but was smaller than event $F$ and projected pyroclasts lower than those from event $\mathrm{F}$. The final video, video IV, was recorded at 14:28 HST on December 8 for 7.30 seconds. It captured event $\mathrm{G}$, which occurred in the center of the southeast sink. Other events occurred just after event $G$, overlapping in time. Events F and G occurred at the southeast sink, which was out of the field of view for the webcam that recorded the 24-hour video. Therefore, these isolated events could not be placed within a 24-hour context, but they were typical of the style of activity observed at the southeast sink during our data collection and at other times.

\section{Pyroclast Dispersal Patterns}

Six of the seven analyzed events ejected pyroclasts symmetrically, generally from the crest of the domed free surface, as the bubble burst. The exception was event $\mathrm{E}$, from which pyroclasts were ejected asymmetrically from only the northwest margin of the bubble. This is likely because the northwest margin rose faster, and so the crust (along the northwest margin) thinned 
faster and burst before the rest of the bubble. All of the observed event $\mathrm{E}$ pyroclasts were ejected on inclined trajectories from the northwest margin. In some cases, local irregularities in the crust where events occurred appear to control pyroclast ejection by controlling the direction of expansion of the bubble.

The symmetrical events exhibited a spectrum of pyroclast dispersal trajectories. At one end of the spectrum, pyroclasts were generally focused more tightly at the top of bubble and were propelled upward in a collimated pattern, with narrow horizontal dispersal. For instance, pyroclasts during event $\mathrm{D}$ were only dispersed to a maximum width of about $6 \mathrm{~m}$. At the other end of the spectrum, pyroclasts tended to fan out in a much wider pattern. For instance, the pyroclasts associated with event $\mathrm{F}$ attained a width of about $17 \mathrm{~m}$. The other symmetrical events fell between these two extremes in terms of the width of dispersal of the pyroclasts.

\section{Eruption Rate and Pyroclast Size and Shape}

We conducted grain size analysis for ejected pyroclasts for the seven events and computed an average mass eruption rate. Pyroclasts ejected on to the crater rim during larger explosions have a very low density of 290 kilogram per cubic meter $\left(\mathrm{kg} / \mathrm{m}^{3}\right)$, indicating that the lava within at least the upper few meters of the lake was in the form of a highly expanded foam prior to disruption. For a calculated melt-phase density of $2,700 \mathrm{~kg} / \mathrm{m}^{3}$, this corresponds to a lava vesicularity of nearly 90 percent. Median equivalent circular diameters for pyroclasts varies in the range of 0.10 to $0.64 \mathrm{~m}$. Mass eruption rate varies in the range of 278 to 3,525 kilograms per second $(\mathrm{kg} / \mathrm{s})$ (table 2). There is no systematic trend in pyroclast size with mass eruption rate, but we note that the two highest intensity events by mass eruption rate (events $\mathrm{F}$ and G) produced the pyroclasts with the smallest median equivalent circular diameter.

We also binned the clast data into phi groupings (negative $\log$ to the base 2 of the particle diameter) from $-11 \phi(2,048$ millimeters [mm]) to $-4 \phi(16 \mathrm{~mm})$ according to the size of the minor axes. Figure 6 plots cumulative mass percentage versus bin size of all of the lower intensity events (A-E) and the two highest intensity events ( $F$ and $G$ ) at Halema 'uma' $u$ alongside two more powerful eruptions - the July 21-24, 2001, sub-Plinian basaltic eruption of Etna (Scollo and others, 2007) and the May 2008 Plinian silicic eruption of Chaitén volcano (Alfano and others, 2016).

The mean cross-sectional area of an individual pyroclast, across events A-G, was $1.8 \times 10^{-2}$ square meters $\left(\mathrm{m}^{2}\right)$; the median cross-sectional area of individual pyroclasts, across events $A-G$, was $2.9 \times 10^{-3} \mathrm{~m}^{2}$. The pyroclast with the greatest area, from event $\mathrm{F}$, measured $2.3 \mathrm{~m}^{2}$. The smallest measured pyroclast area, $1.0 \times 10^{-4} \mathrm{~m}^{2}$, was observed in many events and lies at the resolution limits of the camera. Event $\mathrm{G}$ boasted the pyroclast with the largest perimeter at $24.1 \mathrm{~m}$, whereas the mean perimeter across all events was $0.4 \mathrm{~m}$ (the median was $0.2 \mathrm{~m}$ ) and the minimum perimeter was $0.03 \mathrm{~m}$, again measured in multiple events and indicating the limit of resolution.

We did not find any link between pyroclast shape factors and the intensity of the events. The position on a bubble from which a pyroclast was ejected (that is, center or edge), and the time at which pyroclasts were ejected, also showed no relation with any of the shape parameters. Based on this study, pyroclast

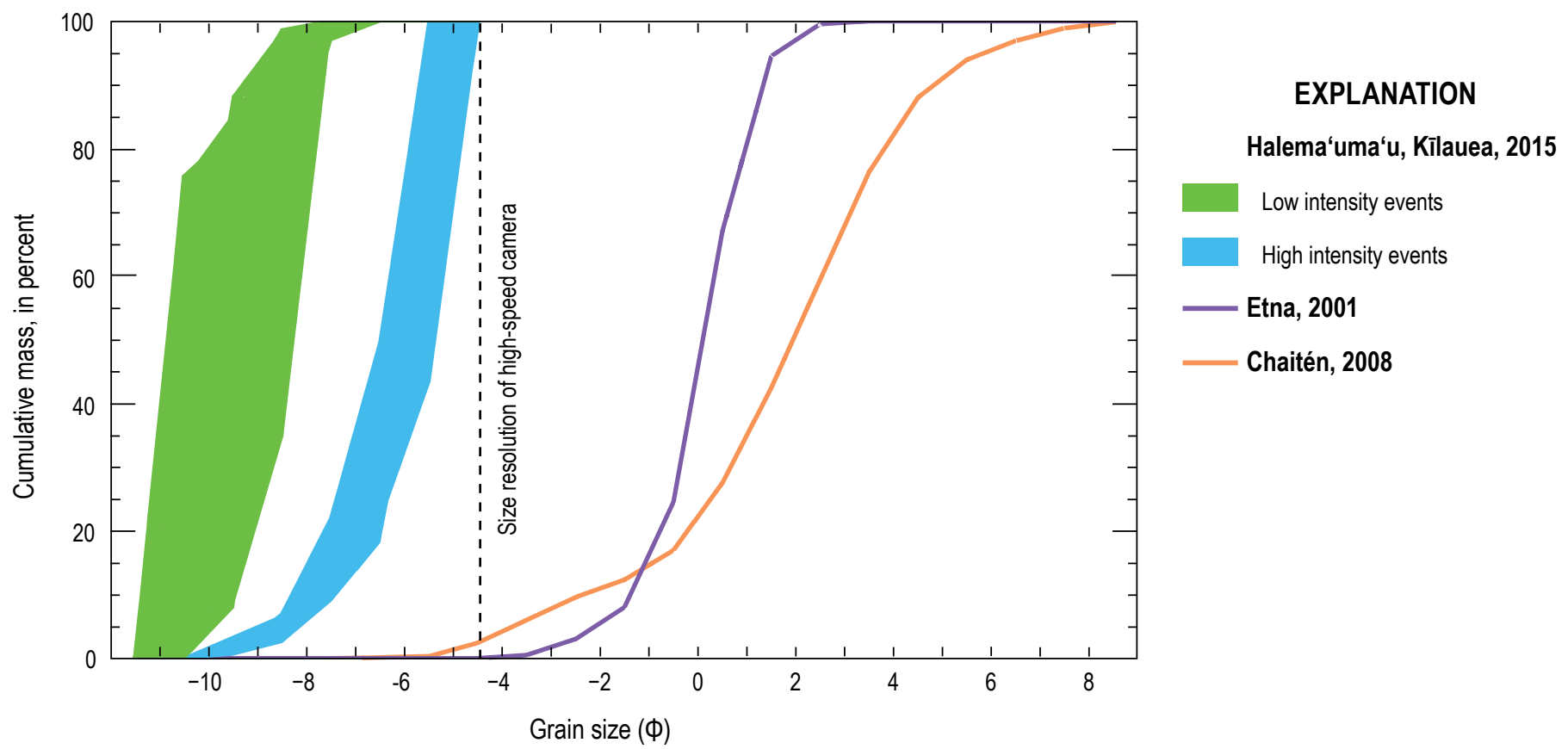

Figure 6. Plot of cumulative mass percent versus grain size for bubble bursting events at Halema'uma'u. The green and blue areas on the plot, respectively representing the low $(A-E)$ and high ( $F$ and $G$ ) intensity events at Halema'uma'u, depict the bounds of the events analyzed in this study. For all the eruptions depicted here, as intensity increases, particles are more poorly sorted (the particles span a wider range of grain size values) and decrease in grain size, indicating a relation between intensity and fragmentation. 
size and shape vary randomly during a bursting event. Of note, both size and shape of pyroclast changes over time owing to in-flight deformation and fragmentation, is also documented by Taddeucci and others (2017) at other volcanoes.

\section{Discussion}

\section{Relations among Parameters for Analyzed Bubble Bursts}

A range of characteristics for the seven bubble burst events we analysed in detail (A-G) are quantified in tables 2 and 3. Although the dataset is relatively small, it does reveal some interesting patterns. The bubble height at bursting was estimated directly from videography. Plotting the measured bubble height, $H$, against the best-fit model height of the bubble at the point of bursting, $h$ (eq. 1), reveals an approximately linear correlation (fig. $7 \mathrm{~A}$ ). The best fit line $\left(\mathrm{R}^{2}=0.84\right)$ is given by the relation

$$
H=0.54 h+0.43
$$

where $H$ and $h$ are in meters. Although it is, perhaps, unsurprising that these two estimates of bubble height are linearly correlated, it does give confidence that the parameter $h$ from equation 1 gives useful information about the size of the bubble at bursting. This indicates that the application of equation 1 to the data is meaningful, which, in turn, indicates that the physical mechanism of the bubble burst is similar to that of larger bubbles bursting at Stromboli (Taddeucci and others, 2012). This is despite the differences in bubble burst geometries at Stromboli, where the bubbles are understood to be confined within a narrow conduit (Blackburn and others, 1976), and Halema'uma' $u$, where the bubbles are either unconfined, or confined only on one side, by the crater wall. A further, practical consequence of this correlation is that equation 2 could be used widely, in cases where the bursting bubble is unseen, to estimate the size of the bubble at burst from measured initial pyroclast velocities.

The data also reveal an approximately linear correlation between bubble burst velocity, $v_{\mathrm{b}}$, and the bubble rise velocity, $v_{\mathrm{r}}($ fig. $7 B)$. The best fit line $\left(\mathrm{R}^{2}=0.78\right)$ is given by the relation

$$
v_{b}=2.5 v_{r}-5.6
$$

where $v_{\mathrm{b}}$ and $v_{\mathrm{r}}$ are in meters per second, indicating that the burst velocity is around 2.5 times greater than the bubble rise velocity. This supports the inference that bubble bursts are driven by overpressure within the bubble, rather than simple disruption of the upper surface of the bubble, where the velocities would be nearly identical. A practical consequence is that equation 3 may allow bubble rise velocity to be inferred from observed burst velocity.
The data also allow us to test whether other parameters are correlated. Although it may be intuitively appealing to expect that the model value of the initial pyroclast velocity at the start of the burst process $v_{0}$ should depend on bubble rise velocity, and particularly on bubble burst velocity, the data do not support thisno correlation is apparent. This suggests that the mechanism of bubble bursting and pyroclast ejection is complex. Our qualitative observations of the bursting process revealed that the jet of pyroclasts produced is variably collimated (see Results section). It is possible that the degree of collimation, and the dynamics of bubble expansion, play important roles in translating the burst energy into pyroclast velocity. Further data would be needed to test this hypothesis.

It is also interesting to note that there is no apparent correlation between the modelled pyroclast initial velocity at the start of the burst process and any of the measured or modelled bubble size parameters. For our dataset, at least, this implies that larger bubbles do not eject pyroclasts at significantly higher velocities than smaller bubbles.

Importantly, there is also no apparent correlation between the bubble rise velocity and any of the measured or modelled bubble size parameters. For scenarios in which bubbles are rising through a liquid, it is usual to find a strong correlation between bubble size and bubble rise velocity - indeed, both theoretical equations and empirical correlations exist for a wide range of regimes of behavior, from slow ascent of small bubbles in the Stokes regime, to rapid ascent of large bubbles in the turbulent regime (Clift and others, 2005). Our data are not sufficient to determine why the bubble rise velocity does not correlate with bubble size, but possible reasons include variable rheology or thickness of the crust above the bubble, the influence of other bubbles rising nearby, or local heterogeneities in density and (or) viscosity in the lava lake.

\section{Depth of Decoupling of the Bubbles}

The bubbles that drive the events we analyzed arrive at the free surface with a substantial rise velocity, on the order of $10 \mathrm{~m} / \mathrm{s}$. Given the lack of correlation between bubble size and rise velocity, it is not possible to infer the depth at which the bubbles decouple from the lava. It is reasonable to suppose that this depth must be at least tens of meters, as any shallower rapid acceleration would had to have approached or exceeded that owing to buoyancy, which does not seem physically plausible. The evidence, presented above, that the bubbles arrive at the surface with overpressure also supports the interpretation that the bubbles must have become decoupled from the lava at a significant depth. However, the lateral motion of the prolonged episodes along the lake surface (fig. $4 E-G$ ) does not appear to be influenced by the circulation of the lake, suggesting that they are shallowly rooted. Some episodes are triggered by rock falls and appear to be boosted or sustained by coalescence processes within the upper few tens of meters of the surface. In reality, different depths may be associated with events, and further work is required to determine the depth of origin of the bubbles that drive the spattering events. 

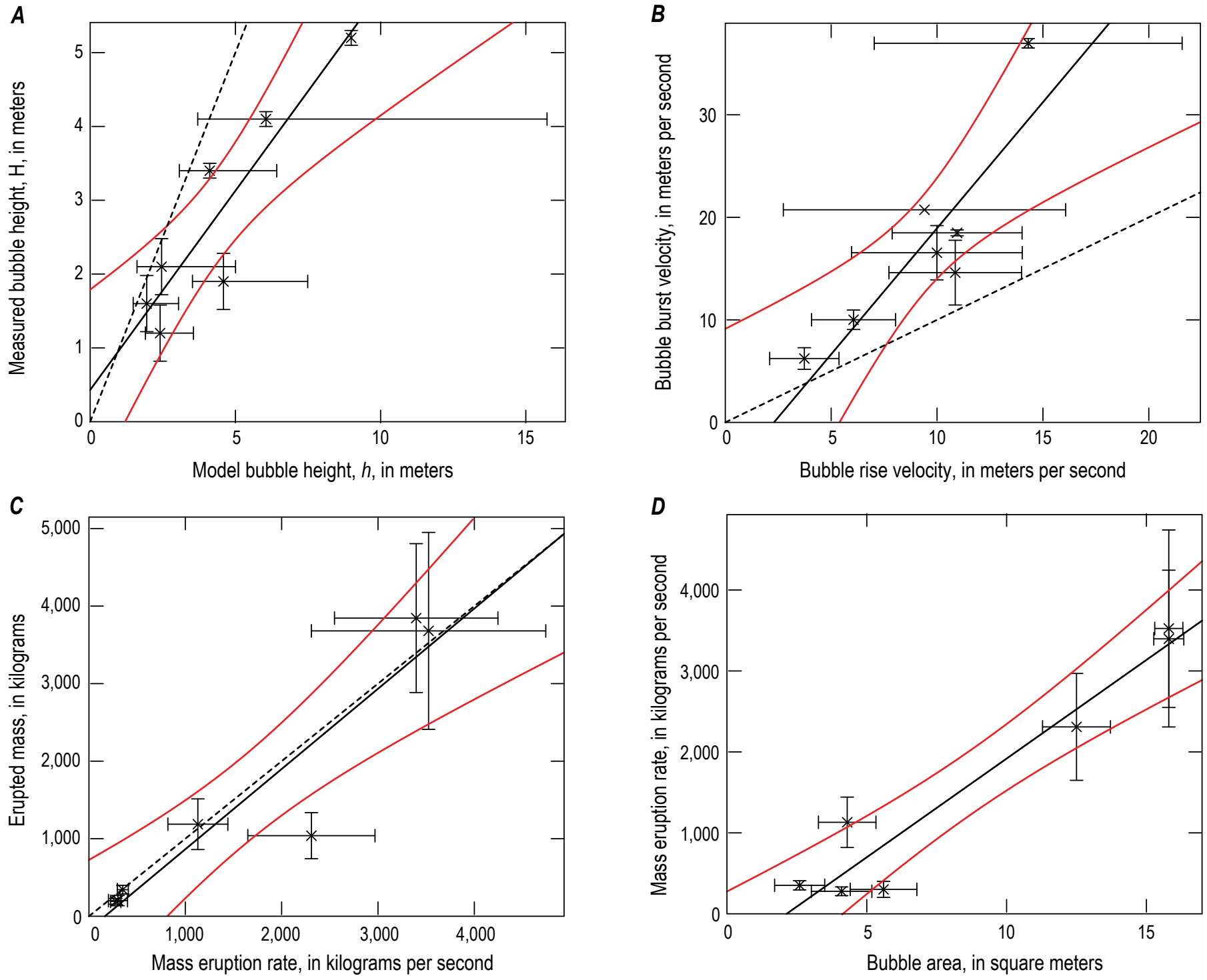

Figure 7. Plots of bubble bursting parameters. Red lines give the 95-percent confidence envelope on the fit. Dashed black line is the 1:1 line. $A$, Measured bubble height, $H$, against the best-fit model bubble height parameter, $h$ (eq. 1 ), for events A-G. The solid black line gives the best fit of a linear model to the data, where $H=0.54 h+0.43\left(R^{2}=0.84\right)$. $B$, Measured bubble burst velocity, $v_{b}$, against mean bubble rise velocity, $v_{r}$, for events A-G. The solid black line gives the best fit of a linear model to the data, where $v_{b}=2.5 v_{r}-5.6\left(R^{2}=0.78\right)$. $C$, The total mass of pyroclasts erupted to the peak of the event (that is, the video frame in which the maximum number of pyroclasts is visible) correlates strongly with the mass eruption rate. Solid black line shows the best-fit line. $D$, The mass eruption rate correlates strongly with bubble area. Solid black line shows the best-fit line.

\section{Mass Eruption Rate}

We use mass eruption rate as our principal measure of intensity of the bubble burst events. On the basis of the mass eruption rate data (table 2 ), we identify relatively low intensity events (A-E) and relatively high intensity events (F and G). There is a strong positive correlation (Pearson correlation coefficient, $\mathrm{R}=0.94$ ) between total erupted mass and mass eruption rate (fig. 7). The best-fit line is very close to the $1: 1$ line, which results from the fact that the typical time from the initiation of the bubble burst to the peak frame (that is, the point at which the maximum number of pyroclasts is visible) is close to 1 second for all events.
Although there is no statistically meaningful correlation between median pyroclast equivalent circular diameter and mass eruption rate, it is noteworthy that the two highest intensity events have the smallest median pyroclast size (table 2). This suggests that higher intensity events are associated with a higher degree of fragmentation. This is, of course, typical of a wide range of volcanic eruption types (Walker, 1973). To explore this further, we compare the distribution of mass with pyroclast size from our data with data from two other eruptions - the 2001 Etna and 2008 Chaitén eruptions (fig. 6). The Halema'uma'u ejecta are relatively well sorted, a general feature of magmatic or dry fall deposits (Houghton and Carey, 2015) and are much coarser than the Etna and Chaitén samples. The 2008 Chaitén eruption (Alfano 
and others, 2016) had a volcanic explosivity index of 4, with 0.5 to 1.0 cubic kilometer tephra volume, whereas Etna from July 19 to 24,2001 , covered an area of $750 \mathrm{~km}^{2}$ with tephra (Scollo and others, 2007). The trend of decreasing grain size (efficiency of fragmentation) with increasing eruption intensity is approximately maintained over many orders of magnitude.

Mass eruption rate has a strong positive correlation (Pearson correlation coefficient, $\mathrm{R}=0.97$ ) with bubble area (fig. $7 D$ ), implying that the size of the bubble exerts a strong control on the intensity of the resulting bubble burst event. However, mass eruption rate does not correlate with bubble rise and burst velocities, or pyroclast initial velocities, and bubble rise and burst velocity do not correlate with bubble size parameters. Therefore, although it may be intuitively appealing to suppose that larger bubbles rise faster, that hypothesis is not supported by the data.

\section{An Intermediary Eruption Style}

Individual bubble-bursting events at Halema'uma' $u$ are weaker and shorter in duration than Strombolian explosions, but, when they merge, they form prolonged episodes that plot between Strombolian explosions and Hawaiian fountains in terms of erupted mass and duration (fig. 8). The Halema'uma' $u$ activity was commonly continuous over timescales similar to Hawaiian fountaining but was markedly less steady than high fountains, and clearly was fed by the arrival of approximately meter-sized individual bubbles. In this fashion, a significant portion of the gas phase was released as discrete bubble bursts, but with frequencies two or three orders of magnitude higher than typical bubble bursts at Stromboli. During prolonged episodes, the closer spacing of the bubble bursts permitted sustained, but not steady, jetting of gas, and ejection of bombs and lapilli. Initial velocities of the ejecta tended to be lower by 1 to 1.5 orders of magnitude than both normal Strombolian explosions and Hawaiian fountains (Taddeucci and others, 2012).

Globally, the intensity of this activity fits on the lower end of basaltic explosive behavior, but in style it sits in a field between typical high fountaining events and normal Strombolian explosions (fig. 8), forming an intermediary eruption style.

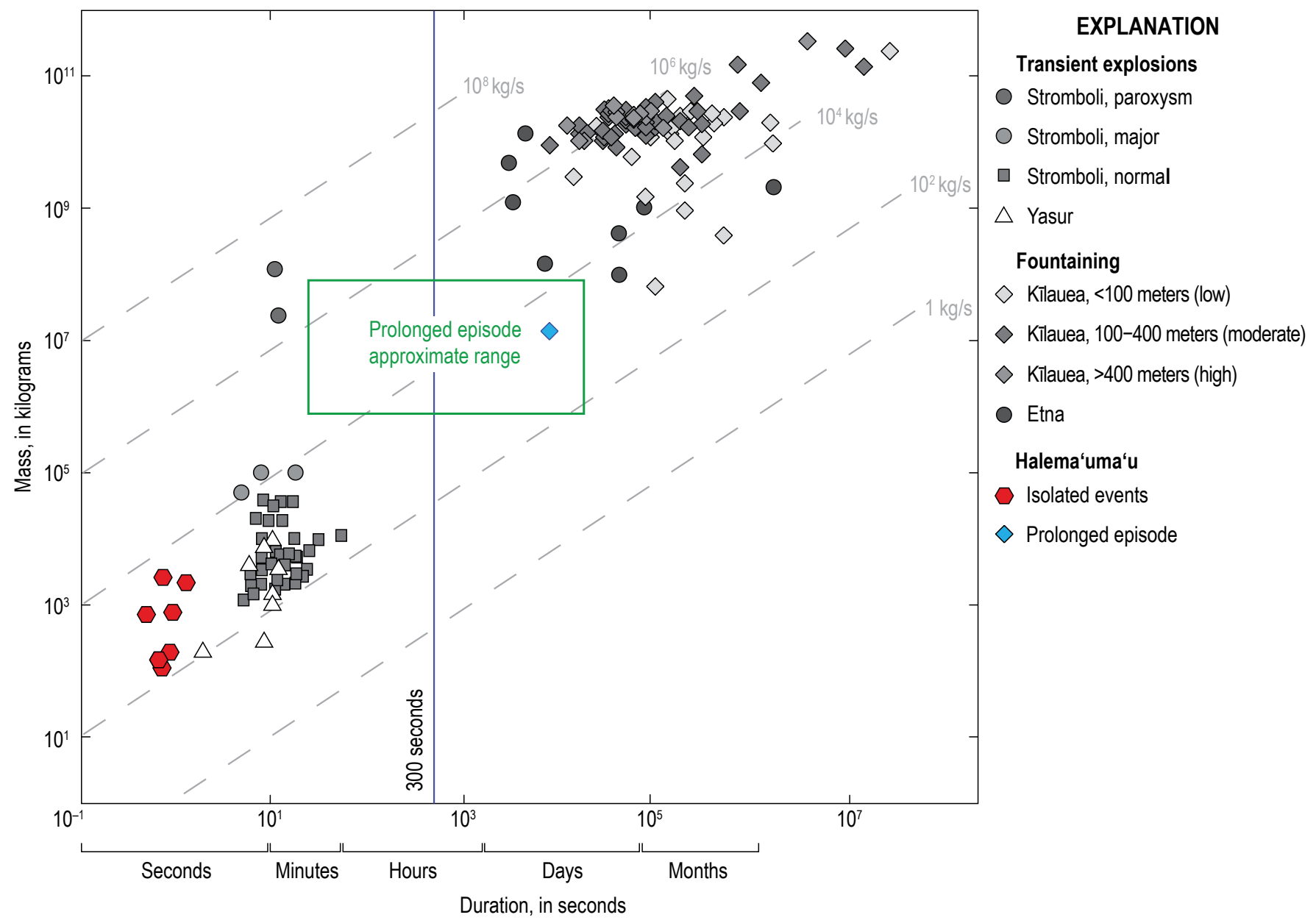

Figure 8. Plot from Houghton and others (2016) of duration and mass of basaltic activity at select volcanoes in grayscale; the results from this study are overlain in color. The gray dashed lines represent equal mass discharge rates. The red hexagons are the seven events (A-G) we analyzed. The blue diamond is the prolonged episode captured in video II from which we quantified four events. The green box shows approximately where prolonged episodes at Halema'uma'u would plot based on the range of durations observed from all the prolonged episodes identified in both of the 24-hour study periods and based on the prolonged episode captured in video II (blue diamond). The duration range indicates that prolonged episodes are an intermediary basaltic eruption style falling between the classical end members. 


\section{Conclusions}

The 2015 activity at Halema'uma'u includes an underdocumented type of behavior exhibited by Kīlauea (and other basaltic volcanoes), previously informally referred to as spattering, but never formally defined in a quantitative fashion. The use of high-speed videography has enabled this eruption style to be described and quantified. The activity sits, in frequency and duration, between weak Hawaiian fountaining and normal Strombolian activity (fig. 8). Consequently, this style of activity adds to the diversity of outgassing patterns known at basaltic volcanoes.

The activity can be classified into three styles: isolated bubble burst events, spatially grouped clusters of events, and prolonged episodes of overlapping events. All these types of spattering activity result from mechanically decoupled large gas bubbles rising buoyantly to the free surface, sometimes triggered by rock falls into the lava lake. This is the first time a detailed classification has been conducted on a basaltic eruption style that was not a classical basaltic end member.

The lack of strong correlation between the rise velocity of bubbles and any of the measured or derived bubble size parameters suggests that bubble rise velocity in the lava lake is subject to complex physical controls, perhaps as a consequence of the highly dynamic, roiling environment during prolonged episodes of spatter, which may lead to rapidly changing heterogeneities in the physical properties (viscosity, density, and velocity) of the lava through which the bubbles are ascending. Equally, the lack of correlation between the initial pyroclast velocity at the start of the burst process and the size of the bubble suggests that local influences modulate pyroclast velocity. These may include variability in the thickness of the fragmenting crust, fine scale heterogeneities in the properties of the melt, and the presence or absence of adjacent rising and (or) bursting bubbles.

\section{References Cited}

Abramoff, M.D., Magelhaes, P.J., and Ram, S.J., 2004, Image processing with ImageJ: Biophotonics International, v. 11, p. $36-42$.

Alatorre-Ibargüengoitia, M.A., Scheu, B., Dingwell, D.B., Delgado-Granados, H., and Taddeucci, J., 2010, Energy consumption by magmatic fragmentation and pyroclast ejection during Vulcanian eruptions: Earth and Planetary Science Letters, v. 291, no. 1-4, p. 60-69, https://doi.org/10.1016/j. epsl.2009.12.051.

Alfano, F., Bonadonna, C., Watt, S., Connor, C., Volentik, A., and Pyle, D.M., 2016, Reconstruction of total grain size distribution of the climactic phase of a long-lasting eruption-The example of the 2008-2013 Chaitén eruption: Bulletin of Volcanology, v. 78, p. 46, https://doi.org/10.1007/s00445-016-1040-5.
Blackburn, E.A., Wilson, L., and Sparks, R.J., 1976, Mechanisms and dynamics of strombolian activity: Journal of the Geological Society of London, v. 132, p. 429-440.

Bonaccorso, A., and Calvari, S., 2013, Major effusive eruptions and recent lava fountains-Balance between expected and erupted magma volumes at Etna volcano: Geophysical Research Letters, v. 40, p. 6,069-6,073.

Clift, R., Grace, J.R., and Weber, M.E., 2005, Bubbles, Drops, and Particles: Mineola, N.Y., Dover Publications, Inc., $384 \mathrm{p}$.

Deike, L., Ghabache, E., Liger-Belair, G., Das, A.K., Zaleski, S., Popinet, S., and Séon, T., 2018, Dynamics of jets produced by bursting bubbles: Physical Review Fluids, v. 3, p. 013603 .

Georgescu, S.-C., Achard, J.-L., Canot, E., 2001, Jet drops ejection in bursting gas bubble processes: European Journal of Mechanics B/Fluids, v. 21, p. 265-280.

Holcomb, R.T., 1987, Eruptive history and long-term behavior of Kilauea Volcano, chap. 12 of Decker, R.W., Wright, T.L., and Stauffer, P.H., eds., Volcanism in Hawaii: U.S. Geological Survey Professional Paper 1350, p. 261-350.

Houghton, B.F., and Carey, R.J., 2015, Pyroclastic fall deposits, in Sigurdsson, H., Houghton, B.F., McNutt, S., Rhymer, H., and Stix, J., eds., Encyclopedia of Volcanoes: San Diego, Academic Press, p. 599-616.

Houghton, B.F., Swanson, D.A., Carey, R.J., Rausch, J., and Sutton, A.J., 2011, Pigeonholing pyroclasts - Insights from the 19 March 2008 explosive eruption of Kîlauea volcano: Geology, v. 39, p. 263-266.

Houghton, B.F., Swanson, D.A., Rauch, J., Carey, R.J., Fagents, S.A., and Orr, T.R., 2013, Pushing the Volcano Explosivity Index to its limit and beyond - Constraints from exceptionally weak explosive eruptions at Kīlauea in 2008: Geology, v. 41, p. 627-630, https://doi.org/10.1130/ G34146.1.

Houghton, B.F., Taddeucci, J., Andronico, D., Gonnermann, H.M., Pistolesi, M., Patrick, M.R., Orr, T.R., Swanson, D.A., Edmonds, M., Gaudin, D., Carey, R.J., and Scarlato, P., 2016, Stronger or longer-Discriminating between Hawaiian and Strombolian eruption styles: Geology, v. 44, p. 163-166, https://doi.org/10.1130/G37423.1.

Kemmer, G., and Keller, S., 2010, Nonlinear least-squares data fitting in Excel spreadsheets: Nature Protocols, v. 5, p. 267.

Kientzler, C.F., Arons, A.B., Blanchard, D.C., and Woodcock, A.H., 1954, Photographic investigation of the projection of droplets by bubbles bursting at a water surface: Tellus, v. 6, p. $1-7$. 
Macdonald, G.A., 1972, Volcanoes: Engelwood Cliffs, N.J., Prentice-Hall, Inc., 510 p.

Mason, B.J., 1954, Bursting of air bubbles at the surface of sea water: Nature, v. 174, p. 470-471.

Mercalli, G., 1881, Natura nelle eruzioni dello Stromboli ed in generale dell'attivita' sismico-vulcanica delle Isole Eolie: Atti Societá Italiana Scienze Naturali, v. 24, p. 105-134.

Neal, C.A., Brantley, S.R., Antolik, L., Babb, J., Burgess, M., Calles, K., Cappos, M., Chang, J.C., Conway, S., Desmither, L., Dotray, P., Elias, T., Fukunaga, P., Fuke, S., Johanson, I.A., Kamibayashi, K., Kauahikaua, J., Lee, R.L., Pekalib, S., Miklius, A., Million, W., Moniz, C.J., Nadeau, P.A., Okubo, P., Parcheta, C., Patrick, M.R., Shiro, B., Swanson, D.A., Tollett, W., Trusdell, F., Younger, E.F., Zoeller, M.H., Montgomery-Brown, E.K., Anderson, K.R., Poland, M.P., Ball, J., Bard, J., Coombs, M., Dietterich, H.R., Kern, C., Thelen, W.A., Cervelli, P.F., Orr, T., Houghton, B.F., Gansecki, C., Hazlett, R., Lundgren, P., Diefenbach, A.K., Lerner, A.H., Waite, G., Kelly, P., Clor, L., Werner, C., Mulliken, K., and Fisher, G., 2019, The 2018 rift eruption and summit collapse of Kīlauea Volcano: Science, v. 363, no. 6425 , p. 367-374, https://doi.org/10.1126/science. aav 7046 .

Orr, T., Houghton, B.F., Taddeucci, J., Del Bello, E., Scarlato, P., and Patrick, M., 2014, The bubble's wake-Localized rebound of Kîlauea's summit lava lake following minor bubble bursts [abs.]: American Geophysical Union, Fall Meeting 2014 abstracts, abstract no. V41D-05.

Orr, T.R., Thelen, W.A., Patrick, M.R., Swanson, D.A., and Wilson, D.C., 2013, Explosive eruptions triggered by rockfalls at Kîlauea volcano, Hawai'i: Geology, v. 41, p. 207-210.

Palma, J. L., Calder, E. S., Basualto, D., Blake, S., and Rothery, D. A., 2008, Correlations between $\mathrm{SO}_{2}$ flux, seismicity, and outgassing activity at the open vent of Villarrica volcano, Chile: Journal of Geophysical Research, v. 113, B10201, https://doi.org/10.1029/2008JB005577.

Patrick, M.R., Orr, T., Sutton, A.J., Elias, T., and Swanson, D., 2013, The first five years of Kîlauea's summit eruption in Halema'uma'u, 2008-2013: U.S. Geological Survey Fact Sheet 2013-3116, 4 p.
Patrick, M.R., Orr, T., Sutton, A.J., Lev, E., Thelen, W., and Fee, D., 2016, Shallowly driven fluctuations in lava lake outgassing (gas pistoning), Kîlauea Volcano: Earth and Planetary Science Letters, v. 433, p. 326-338.

Patrick, M.R., Orr, T.R., Swanson, D.A., Elias, T., and Shiro, B., 2018, Lava lake activity at the summit of Killauea Volcano in 2016: U.S. Geological Survey Scientific Investigations Report 2018-5008, 58 p., https://doi.org/10.3133/sir20185008.

Patrick, M., Orr, T., Swanson, D., Houghton, B., Wooten, K., Desmither, L., Pacheta, C., and Fee, D., 2021, Kīlauea's 20082018 summit lava lake - Chronology and eruption insights, chap. A of Patrick, M., Orr, T., Swanson, D., and Houghton, B., eds., The 2008-2018 summit lava lake at Kîlauea Volcano, Hawai'i: U.S. Geological Survey Professional Paper 1867, 50 p., http://doi.org/10.3133/pp1867A.

Poland, M.P., Miklius, A., and Montgomery-Brown, E.K., 2014, Magma supply, storage, and transport at shield-stage Hawaiian volcanoes, in Poland, M.P., Takahashi, T.J., and Landowski, C.M., eds., Characteristics of Hawaiian Volcanoes: U.S. Geological Survey Professional Paper 1801, p. 179-234.

Scollo, S., Del Carlo, P., and Coltelli, M., 2007, Tephra fallout of 2001 Etna flank eruption-Analysis of the deposit and plume dispersion: Journal of Volcanology and Geothermal Research v. 160 , p. $147-164$.

Taddeucci, J., Alatorre-Ibargüengoitia, M.A., Cruz-Vázquez, O., Del Bello, E., Scarlato, P., and Ricci, T., 2017, In-flight dynamics of volcanic ballistic projectiles: Reviews in Geophysics, v. 55, p. 675-718, https://doi.org/10.1002/2017RG000564.

Taddeucci, J., Alatorre-Ibargüengoitia, M.A., Moroni, M., Tornetta, L., Capponi, A., Scarlato, P., Dingwell, D.B., and De Rita, D., 2012, Physical parameterization of Strombolian eruptions via experimentally-validated modeling of high-speed observations: Geophysical Research Letters, v. 39, L16306, https://doi.org/10.1029/2012GL052772.

Taddeucci, J., Edmonds, M., Houghton, B.F., James, M.R., and Vergnoille, S., 2015, Hawaiian and Strombolian eruptions, in Sigurdsson, H., Houghton, B.F., McNutt, S., Rhymer, H., and Stix, J., eds., The Encyclopedia of Volcanoes ( $2 \mathrm{~d}$ edition): London, Academic Press, p. 485-505.

Walker, G.P.L., 1973, Explosive volcanic eruptions-A new classification scheme: Geologische Rundschau, v. 62, p. 431-446, https://doi.org/10.1007/BF01840108. 
Moffett Field Publishing Service Center, California

Manuscript approved January 20, 2021

Edited by Monica Erdman

Illustration support by Kimber Petersen

Layout and design by Cory Hurd 


\section{这}

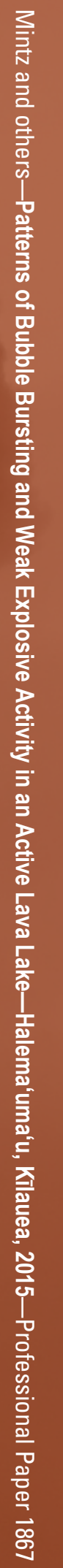

